\title{
Voting as a War of Attrition*
}

\author{
Maksymilian Kwiek ${ }^{\dagger}$ \\ University of Southampton \\ Helia Marreiros \\ Universidade Catolica Portuguesa, Católica Porto Business School, CEGE \\ Michael Vlassopoulos \\ University of Southampton, IZA
}

September 2019 


\begin{abstract}
We study communication in committees selecting one of two alternatives when consensus is required and agents have private information about their preferences. Delaying the decision is costly, so a form of multiplayer war of attrition emerges. Waiting allows voters to express the intensity of their preferences and may help to select the alternative correctly more often than simple majority. In a series of laboratory experiments, we investigate how various rules affect the outcome reached. We vary the amount of feedback and the communication protocol available to voters: complete secrecy about the pattern of support; feedback about this support; public communication; and within-group communication. The feedback no-communication mechanism is worse than no feedback benchmark in all measures of welfare - the efficient alternative is chosen less often, waiting cost is higher, and thus net welfare is lower. Our headline result is that adding communication restores net efficiency, but in different ways. Public communication does poorly in terms of selecting the correct alternative, but limits the cost of delay, while group communication improves allocative efficiency, but has at best a moderate effect on delay.
\end{abstract}

JEL classification: C78, C92, D72, D74

Keywords: voting; intensity of preferences; supermajority; conclave; filibuster; war of attrition; communication.

*This research received support from a University of Southampton SRDF grant and a British Academy/Leverhulme Small Research Grant SG142655. We would like to thank José-Alberto Guerra, Aniol Llorente-Saguer, Kirill Pogorelskiy, and participants of the Warsaw Economic Seminars 2017, the 18th Meeting of the Association for Public Economic Theory 2017 Paris, the Thurgau Experimental Economics Meeting 2018 in Kreuzlingen, and the Economics Workshop at the University of Southampton 2018 for helpful comments. We also thank Abu Siddique, Larissa Marioni and Armine Ghazaryan for excellent research assistance.

†Corresponding author: M.Kwiek@soton.ac.uk, Department of Economics, University of Southampton, Southampton, SO17 1BJ United Kingdom 


\section{Introduction}

We experimentally study a class of voting mechanisms in which voters with privately known intensities of preferences select one of two alternatives through a dynamic game resembling a war of attrition. Our archetypal example is a hiring committee: one of two candidates has to be selected by consensus, defined as the lack of significant opposition. We view the act of resisting one's less favorite candidate as a costly activity. Members of the committee can avoid this cost by withdrawing their opposition. The committee has more than two members, so any pair may be allies who support the same candidate or adversaries who support different candidates. The consensus required for the decision emerges over time as the aggregate opposition towards one of the alternatives falls below a critical value. Our lab experiments bring to light the role of information feedback and communication in enhancing or reducing the conflict, which, in turn, affects the efficiency performance of this voting mechanism.

Examples. There are numerous examples of voting committees that have the features of supermajority requirement, costly delay and communication. Election of the Pope by the College of Cardinals of the Roman Catholic Church is one well-publicized case of the kind of institution we investigate. All cardinals participating in the election repeat voting until a supermajority of $2 / 3$ agrees on one candidate, which, in case of two candidates, is tantamount to the opposition falling below $1 / 3$ of the College. The rules enforce a considerable degree of austerity in the form of the cardinals suffering a personal cost of delaying a decision. ${ }^{1}$ In terms of communication, it can be argued that locking cardinals in one location facilitates deliberation.

Many parliaments and similar assemblies employ supermajority rules at least in some decisions. For instance, the Council of the European Union takes decisions by qualified

\footnotetext{
${ }^{1}$ For instance, Baumgartner (2003, p. 40) describes the first election according to new conclave rules established by Gregory X in 1274 as follows: "The cardinals would be locked in to conclave with just one servant each, although two were permitted for special situations. Gregory mandated that all sleep together in one large room with only curtains to separate their beds. (...) Only one plate of food and a bowl of soup would be provided per person, and after five days this would be reduced to bread, water, and a little wine. There was a timetable for reducing the cardinals' comfort level as conclave dragged on. (...)".
} 
majority, defined by Article 16 of the Lisbon Treaty as 55\% of countries (16 out of 28) representing at least $65 \%$ of the population. ${ }^{2}$ As far as communication between committee members is concerned, we note that any democratic parliament anywhere in the world is a place where members debate - the very word "parliament" means a place where delegates talk.

Even if the committee operates formally according to simple majority rules, the institution of legal obstruction, known as filibuster, creates a similar waiting game with costly delay (Wawro and Schickler, 2006, Dion et al., 2018). In addition to voting yes or no, filibuster enables individual committee members to obstruct the voting process, so that the vote on a bill cannot take place. Particular procedures adopted by the committee define the equivalent supermajority requirement. In terms of the cost of waiting, it is important to note that the delay was costly not only to the obstructionist, but to other senators as well, and that this cost was increasing with time. ${ }^{3}$

Another example is trial by jury, in which unanimity is usually required. After seeing the evidence and testimonies, the jurors vote repeatedly until no one opposes the decision to acquit or convict the suspect. This is combined with deliberations among the jury members. Other examples include corporate strategy committees deciding on the direction of their investment, or the industry standardization process in which companies negotiate to select a standard.

This study. All of these examples are collective choice situations in which simple majority is abandoned in favor of a more complicated set of supermajority rules, waiting

\footnotetext{
${ }^{2}$ In some cases, members may not consider delaying the decision to be the worst outcome, resulting in maintaining the status quo permanently. This type of preferences does not give rise to a war of attrition that we study. Our analysis applies when the committee members agree that one of the alternatives must be selected, while the only effect of reaching this decision after a prolonged waiting is to add costs. Selecting a President is one example. Dealing with an urgent legislation, emergency or a crisis could be another.

${ }^{3}$ Wawro and Schickler (2006, p. 31) write: "If a quorum is not found to be present, the Senate is obligated to either adjourn or dispatch the sergeant at arms to compel the attendance of absent senators. The images of sleep-deprived senators rising from cots to appear on the floor in their pajamas in the middle of the night are humanizing reminders of the costs for those who try to wait out filibusters."

This is not to claim that the only cost of filibuster was the physical fatigue on both sides. There was also the opportunity cost of forgoing other activities such as campaigning, doing other legislative work etc. It has been argued that changing some of the Senate rules in 1970, such as allowing many pieces of legislation to be formally open at the same time, effectively lowered the cost of filibuster.
} 
is costly and committee members can engage in communication. Some of the examples listed above have been analyzed as a war of attrition, but we are the first ones, as far as we know, to view the two sides of a war of attrition as coalitions of independent agents, rather than unitary actors. The aspect that we are specifically interested in are the rules governing how information is revealed to participating voters as the game progresses. We run four treatments. The main comparison is between the Public Communication scenario in which all voters in the committee communicate before the game and observe all messages, and the Group Communication mechanism, in which only voters supporting the same alternative can communicate with each other. Apart from those two, we also run two benchmark treatments with no communication. In the Simple Feedback, the committee members know whether they are in minority or majority initially and know the evolution of support over time, while in the No Feedback they do not know even that. The results of these four scenarios are also compared to two theoretical predictions: the theoretical No Feedback - the only form of war of attrition for which we have robust theoretical prediction - and no communication Simple Majority.

Results. We provide experimental evidence in favor of three general claims regarding the efficiency properties of collective decisions in this setting.

The first one relates to the role of the cost of waiting induced by the supermajority rule. The argument goes like this: since waiting is costly, the exit time of an individual is a signal of the privately known intensity of her preferences; consequently, more determined players have more say in the final outcome. Consistent with theoretical predictions, our first main result is that the supermajority rule is more efficient than simple majority for the parameter values that we use in our experiments. The basic sorting argument at the heart of our model is well-known in auction theory and other fields of economics, but it is under-explored in voting, where monetary transfers are prohibited.

Our second contribution is to demonstrate that apparently small changes in the communication protocol can enhance or reduce the level of sorting and competition between the coalitions. The two types of communication we consider are within-coalition of sup- 
porters and fully public communication among all voters. We find that communication that is restricted to within-group members appears to create a greater conflict between groups, as measured by the expected waiting time. This, however, improves the quality of the committee's choice. Conversely, public communication among all committee members seems to induce a cooperative effect, whereby the committee saves on waiting time. This, however, reduces the quality of the committee's decision.

Our third contribution comes from investigating a naturally emerging asymmetry in our game. Wars of attrition are known to have multiple equilibria, and an ex ante asymmetry may thus lead to fragile equilibrium predictions. In particular, a small perturbation that makes one side only slightly "stronger" may translate into the probability of winning close to one (Nalebuff and Riley, 1985, Myatt, 2005). However, in our experiments we observe that this does not extend to asymmetries in the level of support for the alternatives. Namely, non-pivotal majority players have a tendency to exit early, and, therefore, the support tends to become more equal at the beginning of the game. In other words, we find evidence that the minority is empowered by supermajority rules in comparison to simple majority even in this potentially fragile dynamic context. Our theory alone is incapable of delivering this result.

\section{Literature}

Our paper contributes to three different strands of the literature: on wars of attrition, on efficiency of mechanisms with preference intensity and on communication in broadly understood group contests.

From the point of view of the theoretical literature, our paper is closely related to studies on wars of attrition, which, of course, is a classical topic. The benchmark model has been studied by Smith (1974). Many subsequent contributions emphasized the multiplicity of equilibria that characterize two-player wars of attrition; see, for example, Nalebuff and Riley (1985), the summary in Fudenberg and Tirole (1996), section 4.5.2., as well as Krishna and Morgan (1997), or Myatt (2005). 
Sometimes, collective choice in a committee is simplified into a two-player war of attrition such as the already mentioned study of filibuster by Wawro and Schickler (2006) and Dion et al. (2018). ${ }^{4}$ Multiplayer wars of attrition have been studied by Bulow and Klemperer (1999). Our paper differs in that we study a collective choice problem with two alternatives, while Bulow and Klemperer (1999) consider a rivalrous good allocation problem. A closer version to ours is presented in Ponsati and Sakovics (1996), who, like us, consider voting on only two alternatives, but in contrast to us, they focus on the positive question of equilibrium uniqueness and contemplate only the rules that closely correspond to our No Feedback mechanism.

The efficiency of mechanisms similar to the ones studied in the present paper was analyzed in Kwiek (2014). The question there was about the effect of the size of supermajority on what we call below allocative efficiency. Welfare analysis in the present paper is of the "second-best" type too, as we also restrict ourselves to this type of timing games. If any general incentive compatible mechanism could be used, then a vast mechanism-design literature provides a number of results; for example, a Vickrey-ClarkeGroves mechanism achieves efficient outcome in dominant strategies, when the welfare criterion is allocative efficiency or when transfers are allowed (Vickrey (1961), Clarke (1971), Groves (1973)). Kwiek (2017) studies a general class of voting games without transfers but with penalties, to which our game belongs.

The experimental literature testing wars of attrition is not very large. Hörisch and Kirchkamp (2010) and Oprea et al. (2013) investigate wars of attrition with two players and independent private information. In a prequel to this paper (Kwiek et al. 2016), we use a simplified two-value framework to confront the basic hypothesis that supermajority may be more efficient than simple majority, and that heterogeneity of preference intensities is a determinant of how strong this effect is. This is tested in both static and dynamic versions of the game, although we do find systematic differences between these

\footnotetext{
${ }^{4}$ Bawn and Koger (2008) also study filibuster as a two-player game with intensity of preferences. Their game, however, resembles a first-price auction like in models of lobbying, rather than a second price auction like a war of attrition.
} 
two formats. The current paper extends this result to a continuous distribution of values. More importantly, it then explores the role of feedback and communication.

Moving on to the literature on experiments in voting, Palfrey (2012) in his comprehensive survey of experiments in political economy devotes one section to mechanisms that reflect preference intensity. The mechanisms he reports are based on the idea of linking many voting decisions together. ${ }^{5}$ The mechanism in the current paper differs from these studies in that it is concerned with a voting decision on a single issue, rather than leveraging one issue against another.

It has been established some time ago that cheap-talk communication may change outcomes of the interaction, even if the players have conflicting interests (e.g. Matthews, 1989, Matthews and Postlewaite, 1989). Martinelli and Palfrey (2017) provide a survey on recent developments in an experimental literature on the role of communication in collective decision-making. Several previous papers have investigated the impact of communication on turnout and the efficiency of voting outcomes (for example, Grosser and Schram (2006) or Goeree and Yariv (2011)).

Closer to our work, there is a rich literature on collective choice among groups of players, in which the distinction between public communication and within group communication is the main subject of investigation. Our base game is different than in each of these, in some cases quite drastically, but in a very general sense, our study echoes some of the results.

Specifically, Brookins et al. (2018), Cason et al. (2012 and 2017), Leibbrandt and Sääksvuori (2012), Sutter and Strassmair (2009) and Rapoport and Bornstein (1989) study within group communication in static tournaments between teams. Here, some critical differences are worth emphasizing: first, our game is explicitly dynamic; second, our game has a different payoff structure (akin to the second-price rather than first-price

\footnotetext{
${ }^{5}$ For example, Casella (2005) hypothesizes that storable votes, deployable over time in voting decisions of particular importance to an individual, may help to express the intensity of voters' preferences; Casella et al. (2006) are the first of a few studies to test this mechanism in a laboratory experiment. A more general version of this idea (involving not necessarily sequential voting) is developed by Jackson and Sonnenschein (2007) and tested by Hortala-Vallve and Llorente-Saguer (2010).
} 
auction); third, our game is with incomplete information calibrated in such a way that a more severe conflict may potentially improve efficiency of the mechanism; forth, the size of the groups evolves over time and, thus, it is in this sense endogenous. Yet, one of our results - that within group communication makes the group more aggressive vis-à-vis the other group — is also one of the messages that emerge from that literature. ${ }^{6}$

Kittel et al. (2014), Palfrey and Pogorelskiy (2017) investigate a one-shot voting decision, while ours is a dynamic mechanism that could be described as repeated voting on a single issue. However, our and their environments assume that voting is costly, so, not surprisingly, we observe a similar equilibrium response: abstention in their model and an early exit in ours. Since their environment assumes no differences in intensity of preferences, abstention caused by the cost of voting is welfare-reducing. In contrast, the intensities of preferences are heterogeneous and private in our environment, so the cost of voting becomes a sorting device that may enable more efficient outcomes in an appropriately fine-tuned voting mechanism (see also Baron et al., 2017).

\section{Theory: environment, mechanism and some re- sults}

The essential ingredients of our model are the set of $n$ voters and the set of two alternatives $k \in\{A, B\}$, one of which must be selected.

The payoff that each voter receives depends on the outcome, which consists of two elements. The first element is the alternative that is collectively selected, and the second is the length of time that the individual waits.

With regards to attitudes towards alternatives alone, player $i$ prefers one of the al-

\footnotetext{
${ }^{6}$ Dechenaux et al. (2015) presents a survey of experimental literature on contest games, while Sheremeta (2018) does the same for the literature on contests among teams. The latter survey reports a list of topics that emerge while studying group contest games, such as the impact of exogenous group sizes, heterogeneity of players, or the specifics of payoff functions on both the benefit and cost sides. For each of these, there is a closely related question in wars of attrition. While we do not address these questions here, we hope that these connections will be explored in further research.
} 
ternatives (ordinal component) with some intensity (cardinal component). The set of players who support the same alternative will be called a group.

The ordinal component is captured by variable $a_{i} \in\{A, B\}$ denoting which alternative player $i$ prefers; for example, $a_{i}=A$ (or simply $i \in A$ ) means that $i$ prefers $A$. The intensity of preferences of voter $i$ is captured by variable $x_{i} \geq 0$. This cardinal component makes statements like "I am almost indifferent between $A$ and $B$, but prefer $A$ slightly" and "I strongly prefer $A$ to $B$ " meaningfully different. In both cases, $i \in A$, but in the former $x_{i}$ is closer to zero than in the latter. The second element that determines the voter's payoff is the cost of waiting. Let $t_{i}$ be the length of time that $i$ is forced to wait. Ultimately, her payoff is $x_{i}-t_{i}$ if her preferred alternative $a_{i}$ is selected, and $-t_{i}$ if it is not. ${ }^{7}$

This study focuses on an environment in which both ordinal and cardinal components of preferences are private information. Thus, voter $i$ is the only one to know which alternative she prefers and how intensely. From the perspective of all external observers, including other voters, these are random variables drawn from commonly known distributions. In particular, assume that voters may prefer $A$ or $B$ with equal probability. Assume also that random variable $X_{i}$, whose realization is $x_{i}$, is statistically independent across $i$ and has a c.d.f. $F$ and density $f$, common for all voters. The reciprocal hazard ratio associated with this random variable, $H(x)=(1-F(x)) / f(x)$, will later turn out to be an important object. ${ }^{8}$

This environment fits the standard mechanism design problem with quasi-linear pref-

\footnotetext{
${ }^{7}$ It is natural to ask if the results of our study are robust to a possibility of asymmetric time preference. For example, if voters on one side are known to be more impatient ex ante, the welfare properties of the supermajority mechanism would be different than in the symmetric case. Moreover, even if the time preference is asymmetric only ex post, there may be welfare effects of its magnitude. A more detailed discussion of this prospect, along with a possible model formulation, are in Kwiek (2014, 2017). In our experiments, the waiting cost is expressed in monetary terms and - to the extent that this monetary payment fully captures time preferences - it is symmetric.

${ }^{8}$ This contrasts with the common value models as in Condorcet's jury theorem. Thus, our study is not about persuasion, whereby the committee members try to aggregate dispersed evidence to discover the unknown common value. We do not perceive this alternative view of committee deliberations as contradictory. That is, while such common value component may be important in some of the examples above, as soon as the committee members have some non-common preferences, the effects we study begin to matter.
} 
erences. We call $t_{i}$ the nontransferable waiting cost, but it may also be interpreted as a transferable payment to a third party, for example, a tax. Either way, we postulate that interpersonal comparisons of individual payoffs are possible, and therefore one can define various welfare criteria based on cardinal preferences. In this paper, we adopt utilitarian efficiency, whereby welfare is defined as the sum of individual payoffs.

Depending on the context, it may be reasonable to focus on allocative welfare, where the total waiting cost of $\sum_{j} t_{j}$ is ignored, and the welfare is defined simply as a sum of intensities for all voters whose preferred alternative is selected. That is, if $k$ is selected, then the allocative efficiency is $\sum_{i \in k} x_{i}$. A second reasonable criterion is net welfare, which includes the cost of waiting. Namely, if $k$ is selected then net welfare is $\sum_{i \in k} x_{i}-\sum_{j} t_{j}$. Thus, the three measures we are interested in are linked through

Net welfare $=$ allocative welfare - waiting cost.

Net welfare is more valid if the whole population are members of the committee and so the waiting cost is a social loss. Allocative welfare may be more relevant if the committee's decision has a huge externality on a wider population. If the committee consists of representatives of the institution or a wider population, waiting costs of individual committee members are too irrelevant to count. For example, in papal conclave, it is reasonable to claim that personal suffering of cardinals due to spending a few days electing the Pope should not be included in assessing the quality of the decision for the Church; likewise, the personal cost of jurors should not count in comparison with the quality of decision-making for the justice system.

We do not frame our mechanism explicitly as repeated voting, but rather - as in ascending auctions - we adopt an old metaphor of a clock. All $n$ voters start the game by supporting their preferred alternative. As the clock starts ticking, the waiting cost begins to accumulate. The action of each voter is to irreversibly withdraw opposition to the less preferred alternative at the time of their choosing. This action prevents further 
cost increases for the individual, but her waiting cost accumulated thus far is sunk. Therefore, we investigate a type of a war of attrition with many players, but only with two possible alternatives.

A key feature of the mechanism is the level of consensus or supermajority required for the decision. We frame this in terms of the minimal blocking minority, which we denote as $m$. It is a number of voters who, by voting in unison on one alternative, can prevent the other alternative from being selected at that particular moment. In other words, actively supporting one alternative is equivalent to actively opposing the other one. After voters register their support for one of the alternatives, they declare when they cease supporting that alternative. When the support for either alternative falls below $m$, the clock stops. The alternative whose support fell below that threshold is rejected by the committee, and the other alternative is selected. For example, the minimal blocking minority of one, $m=1$, represents the case in which one voter is able to veto an alternative, which amounts to unanimity. Another polar case is $m=(n+1) / 2$ (where odd $n$ is the size of the committee), which represents simple majority.

In all our experiments, we consider the absolutely simplest case, where there are $n=3$ voters (one supporting one alternative, and two supporting the other one) and one player is enough to block an agreement, $m=1$. We compare this waiting game to simple majority, $m=2$, where no waiting occurs. ${ }^{9}$

\subsection{Incentive compatible mechanisms}

An important benchmark mechanism that may be used in the above environment is simple majority. Voters are asked to express their ordinal preferences and the alternative which gathers a majority support is selected. Since the game ends instantaneously, the waiting cost is zero. Allocative welfare and net welfare are the same by construction.

There exist a myriad mechanisms using penalties, such as waiting time, or other

\footnotetext{
${ }^{9}$ We do not focus on the size of supermajority in the current study. For the theoretical treatment of this issue see Kwiek (2014).
} 
payments. To characterize any Bayesian incentive compatible mechanism, we take advantage of the standard tools developed by Myerson (1981). We then check how those results apply to the class of mechanisms we study.

Fix a mechanism and its equilibrium. Define $p_{k}(a, x)$ to be the equilibrium probability that alternative $k$ is selected if the realization of ordinal and cardinal preferences for all agents is $(a, x)$, where $a=\left(a_{1}, \ldots, a_{n}\right)$ and $x=\left(x_{1}, \ldots, x_{n}\right)$ are the profiles of, respectively, ordinal and cardinal components of voters' preferences. Let $P_{k}\left(a_{i}, x_{i}\right)=E_{A_{-i}, X_{-i}} p_{k}(a, x)$ be the corresponding expected probability, if the realization of $i$ 's type is $\left(a_{i}, x_{i}\right)$ (notation: $E_{X} f(x)$ indicates the expected value with respect to random variable $\left.X\right)$. Let also $\pi_{i}\left(a_{i}, x_{i}\right)$ be the associated equilibrium payoff of $i$, and $C_{i}\left(a_{i}, x_{i}\right)$ the associated expected waiting cost. Modifying the results by Myerson (1981) we obtain (Kwiek, 2017):

Lemma 1. A given mechanism is incentive compatible if and only if $p_{k}(a, x)$ and $\pi_{i}\left(a_{i}, x_{i}\right)$ satisfy conditions: (i) $P_{a_{i}}\left(a_{i}, \cdot\right)$ is non-decreasing, (ii) $\frac{\partial}{\partial x_{i}} \pi_{i}\left(a_{i}, x_{i}\right)=P_{a_{i}}\left(a_{i}, x_{i}\right)$, and (iii) $P_{a_{i}}\left(a_{i}, 0\right)=P_{a_{i}}\left(-a_{i}, 0\right)$ and $C_{i}\left(a_{i}, 0\right)=C_{i}\left(-a_{i}, 0\right)$.

Moreover,

Lemma 2. Net expected welfare of voter $i$ in an incentive compatible mechanism is

$$
N W_{i}=E_{A_{i}} \pi_{i}\left(a_{i}, 0\right)+E_{A_{i}, X_{i}} P_{a_{i}}\left(a_{i}, x_{i}\right) H\left(x_{i}\right)
$$

Allocative expected welfare is

$$
A W_{i}=E_{A_{i}, X_{i}} P_{a_{i}}\left(a_{i}, x_{i}\right) x_{i}
$$

That is, the expected net payoff of voter $i$ depends only on two objects, the payoff of the indifferent type, $\pi_{i}\left(a_{i}, 0\right)$, and the allocation function $p_{k}(a, x)$. Knowing them is enough to characterize the overall welfare performance of this mechanism-equilibrium pair, at least in theory. 


\subsection{The symmetric benchmark: No Feedback}

Coming back to the subject matter of this paper, we investigate a particular class of mechanisms. Specifically, the supermajority rule determined by parameter $m$ induces a waiting game in which action of each voter is their time of exit. An individual voter pays the cost of waiting that depends linearly on their time of exit. ${ }^{10}$

The result described in Lemma 2 applies to all the mechanisms that we consider. If only it were possible to characterize equilibrium $\pi_{i}\left(a_{i}, 0\right)$ and $p_{k}(a, x)$ for a given set of voting rules, then we would know the mechanism's theoretical welfare, both net and allocative. Different types of mechanisms may, of course, result in different expected payoffs and allocation functions, and it is difficult to say what they are without a full equilibrium analysis.

There is one set of voting rules, however, for which it is possible to theoretically characterize welfare performance. The No Feedback mechanism with individual cost is a game with the following simple timing and cost rules:

Voters sit in individual rooms or cubicles. At the beginning of the game, they are asked to announce their preferred alternative. They are also told to do nothing for as long as they want to keep supporting that alternative after the waiting starts. By irreversibly pressing the exit button, they make the total support for that alternative drop by one. Then, the alternative whose support falls below a threshold of minimal blocking minority, $m$, is declared the losing alternative, while the other one is announced to be selected by this committee. Because they are kept in individual rooms, voters are never informed about how many other voters support which alternative and how this pattern changes over time. Pressing the exit button freezes further cost increase.

The strategy in this game is essentially the time of exit as a function of intensity $x_{i}$. As long as anonymity can be preserved, the game is and continues to be symmetric

\footnotetext{
${ }^{10}$ This assumes that individuals can avoid further cost increases by leaving the committee proceedings, if not physically, then at least mentally, even if the committee has not reached a decision. For example, individuals may actively quarrel with others, which is a costly activity, but after giving up, they may avoid any extra waiting cost by allowing their mind to drift away (for example, with the help of their internet-enabled wireless devices).
} 
as the time passes; it is, therefore, reasonable to assume that all voters use symmetric strategies.

Assumption 1. Symmetry: in equilibrium, all players' exit time is a function of intensity only, and, moreover, all players use the same function.

Under Assumption 1, we can easily deduce $p_{k}(a, x)$. Define $\tilde{x}_{k,(m)}$ to be the $m$ th order statistic of the vector of intensities of voters who prefer $k .^{11}$ It is evident that under the assumption of symmetric strategies, the allocation function is

$$
p_{A}(a, x)= \begin{cases}1 & \text { if } \tilde{x}_{A,(m)} \geq \tilde{x}_{B,(m)} \\ 0 & \text { otherwise }\end{cases}
$$

Moreover, because any voter, including the one with zero intensity has an option to avoid incurring any cost by exiting immediately, we can conclude that the equilibrium payoff of a voter with zero intensity of preferences is zero, $\pi_{i}\left(a_{i}, 0\right)=0$.

\subsection{Asymmetry in a war of attrition}

In this subsection, we lay out our case why a theoretical analysis of the type presented above is not sufficient and why we might benefit from experimental investigation.

No Feedback voting is easy to implement in practice, but we are not aware of any reallife examples of such mechanism. Realistic dynamic voting rules of the type we consider here have at least the following feature: all participants of the game can see the evolution of support for each alternative. We call this feedback, which will be present in all the remaining mechanisms that we consider.

As soon as we introduce feedback, the asymmetry becomes an inherent feature of the game, making Assumption 1 untenable. Namely, it is unreasonable to expect that the equilibrium exit time depends solely on the intensity of preferences and not on the group

\footnotetext{
${ }^{11}$ That is, the $m$ th largest element of this vector; if $m$ is larger than the number voters supporting $k$, then $\tilde{x}_{k,(m)}=0$.
} 
membership. Therefore, we expect the equilibrium strategies to be asymmetric, but we will assume that the following property holds.

Assumption 2. Group-Symmetry: in equilibrium, all players' exit time is a function of intensity, group membership (minority or majority) and public history of exits. Moreover, all players in each group use the same function.

The problem with asymmetry goes beyond a simple fact that asymmetric games admit asymmetric equilibria. It is known that there are multiple equilibria in a standard twoplayer war of attrition. Likewise here, the following strategy profile is an equilibrium in a game with feedback: all voters in one group exit immediately, and all voters in the other group keep supporting their own alternative - no matter what stage the game reached and regardless of voters' intensity of preferences. As a result, the game in this equilibrium ends immediately and one group wins the vote with probability one. We will call this extreme outcome asymmetric collapse. There are two equilibrium outcomes with asymmetric collapse - one in which the majority wins and one in which the minority wins - but there are also many other equilibria in between these two polar cases.

Of course, asymmetric collapse has profound efficiency consequences. If, for example, the majority is so aggressive that it wins always, then the supermajority rule just replicates the outcome of the simple majority rule. If, on the other hand, the minority ends up being so aggressive that it wins always, then a far worse welfare outcome than simple majority is obtained.

Consider now equilibria in which asymmetric collapse does not occur. If both sides of the voting game win with probability sufficiently far from zero, then other possible phenomena are worth studying because they are relevant for welfare. In particular, we define the following two patterns of behavior. Instant exit occurs when all voters in one group, except precisely $m$ of them, exit immediately. Consequently, if there is instant exit within both groups in the game, then we would observe an immediate wave of exits, followed by a phase of waiting when nothing happens until a single exit triggers the end of the game. It is perhaps worth emphasizing that instant exit and asymmetric collapse 
are distinct concepts. If asymmetric collapse occurs then instant exit cannot even be identified, but if it does not then instant exit might occur, but whether it does has to be checked separately.

The second effect is group sorting, which occurs when members of one group exit in order of their intensity of preferences: the lowest first, then the second lowest etc. Group sorting is an expression of efficient coordination within the group. ${ }^{12}$

We hypothesize that the mechanisms with feedback have monotonic equilibria satisfying Assumption 2, in which instant exit and group sorting occur.

Without providing a formal proof, this type of equilibrium can be explained in the following way. Group-symmetry means that all players within the same group follow the same strategy which describes the time of exit as a function of history of previous exits and an increasing function of intensity of preferences. Thus, the focus on groupsymmetric monotonic strategy profiles guarantees group sorting. The process of exits lasts until only $m$ active players remain in this group. We assume that in the theoretical model it is possible for these exits to occur as an instantaneous cascade (as in Bulow and Klemperer, 1999), leading to instant exit. The waiting game that ensues after instant exit is essentially a two-player war of attrition among the voters whose values are $m$ th order statistics, that is, $\tilde{x}_{A,(m)}$ and $\tilde{x}_{B,(m)}$. Clearly, there are multiple equilibria in this subgame too, exactly like in the standard two-player war of attrition. ${ }^{13}$

\footnotetext{
${ }^{12}$ Bulow and Klemperer (1999) identified instant sorting in their mechanism. Although their environment is somewhat different, instant sorting is similar to our instant exit and group sorting taken together. Myatt (2005) uses term instant exit to mean something closer to what we call asymmetric collapse.

${ }^{13}$ As a digression, we can ask if among those equilibria there exits one that generates the same allocation function as obtained in the No Feedback symmetric model, that is, the allocation function defined in equation 2. The answer is negative, as long as two groups have a different size initially (which is the case in our experiments). Consider a phase of the war of attrition after the wave of instant exits with perfect group sorting. If $\beta_{j}(t)$ denotes the inverse exit function the pivotal player $j\left(\beta_{j}(t)\right.$ is interpreted as the intensity of preferences of $j$ that exits at $t$ ), the first order condition for pivotal bidder $i$ is

$$
\frac{\partial \beta_{j}(t)}{\partial t}=\frac{1-F_{j}\left(\beta_{j}(t)\right)}{f_{j}\left(\beta_{j}(t)\right) \beta_{i}(t)}
$$

where $F_{j}$ and $f_{j}$ are c.d.f. and p.d.f., respectively, of the value of the pivotal player $j$ (distributions of the $m$ th order statistic). Suppose the allocation function defined by equation 2 arises. Then the bidding functions of the two pivotal players in the phase following instant exit must be the same, and so would be their inverses, and their slopes. Thus, it must be that the inverse hazard functions associated with $F_{j}$ and $F_{i}$ are the same, which holds only if these two distributions are the same. They are the same only
} 
We do not characterize the theoretical conditions that pin down these equilibria, because even if we did find them, we would be still left with no guidance as to which equilibrium is more likely to emerge. We cannot appeal to symmetry of the underlying game. Instead, we will employ experimental methods to illuminate the actual welfare performance in our mechanisms. In particular, trying to understand the effects of asymmetry, we search for evidence of asymmetric collapse and for signs as to who is empowered by the majority-minority status.

\section{$3 \quad$ Experimental design and predictions}

All our experiments have the following features in common; all of them are known to the participants because they were explained or can be deduced.

All committees have three voters, $n=3$. We make it impossible that there are committees in which all voters support the same alternative. That is, from the perspective of an individual voter, there are only two possibilities: either she is a member of a majority group of two voters against a lone opponent, or she is a sole voter against a group consisting of two opponents. Since each voter supports each alternative with probability $1 / 2$, the voter is in a minority group with probability $1 / 3$.

All our experiments assume supermajority characterized by $m=1$. We simplify the decision problem of each voter by forcing them to start the game voting for their favorite alternative. They choose only the time of their exit. Therefore, there are three possible ways in which the game can evolve. Either the minority voter gives up first, thus ending the game. Or one of the majority voters exits first, moving the game into a phase in which each of two remaining players supports a different alternative. In this case, either the minority voter exits and thus stops the game, or the remaining majority voter exits and thus stops the game.

In comparison to the real-life examples of repeated voting, we do put a considerable if the initial sizes of two groups (and therefore the number of players who exited in the wave of instant exits) are the same. 
structure on the mechanisms. Firstly, the agents in our experiment are forced to start the game by voting for the alternative that they prefer. What is more important, they cannot masquerade themselves as members of the other party and participate in their group discussion. Finally, ceding to support their alternative is an irreversible decision. We believe that these restrictions are acceptable as an initial approximation, especially in the game with private valuations, where the main concern is the intensity of preferences rather than learning what the values are and which alternative to support.

As a digression, note that simple majority, $m=2$, is one possible mechanism, but its performance does not have to be verified experimentally. Since in all our mechanisms voters are forced to start the game by voting for their favorite alternative, the outcome of simple majority requires no decision: the majority wins with probability one without any delay. ${ }^{14}$

The intensity of preference, measured in Experimental Monetary Units (EMU) can vary from 1 to 60 and so it is (almost) continuous. The probability distribution function (p.d.f.) is depicted in Figure 1. The mean is 12.8 EMU and the median is 6 EMU. Therefore, it is very likely that voter's value of the preferred alternative is small, but it is also possible that the value is very high relative to the expected value.

This particular distribution of preference intensities generates particular average welfare scores. Since the average intensity of an individual is 12.8, simple majority generates on average 2 times this value, or 25.7, the average sum of all three intensities is 3 times this value, or 38.5, and, finally, first best allocation results in $E \max \left\{\sum_{i \in A} x_{i}, \sum_{i \in B} x_{i}\right\}$, which can be calculated to be 30.2 .

\subsection{Treatments}

The four mechanisms described in general terms correspond to four laboratory treatments.

\footnotetext{
${ }^{14}$ If voters in a simple majority mechanism had a chance to vote freely on any alternative, we believe that they would vote sincerely on their preferred one if there was no communication prior to the game. However, it is conceivable that with communication, particularly public, a high-value minority voter may be able to convince two low-value majority voters to concede. It would be worth checking the incidence of such "altruistic" behavior in an experiment.
} 


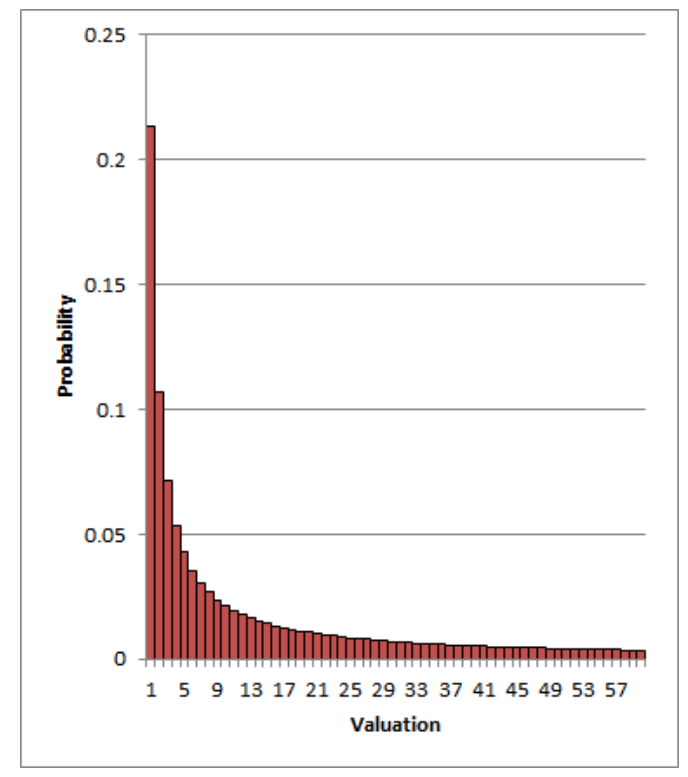

Figure 1: P.d.f. of preference intensity, $f\left(x_{i}\right)$

No Feedback (NF): At the beginning of the game individual voters are told their individual intensity of preferences, $x_{i}$. After the clock starts, voters can exit at any time. By doing that, they make the total support for that alternative drop by one. Then, the alternative whose support falls below a threshold of minimal blocking minority, $m=1$, is declared the losing alternative, while the other one is announced to be selected by this committee. Voters are never informed about how many other voters support which alternative and how this pattern changes over time.

The No Feedback mechanism that we test experimentally enforces anonymity in a deliberate way. The strategies used by voters cannot depend on things that are not observable, such as the identity of other players in the game, the majority-minority status, the pattern of play, or the name of the alternative. ${ }^{15}$ Thus, we are confident that the players in the experiment behave symmetrically. ${ }^{16}$

Once we accept plausible Assumption 1 and apply the insights of Lemma 2, we can simulate the average equilibrium welfare performance of this No Feedback committee:

\footnotetext{
${ }^{15}$ In instructions for participants of the experiments we avoid calling the alternatives names, such as Right or Left, or even $A$ or $B$. We just describe them as "your preferred alternative" and "the alternative you do not prefer" or something similar.

${ }^{16}$ Of course, participants may have a player-specific unobservable type, or face an unobservable preference shock in one particular game, making the exit function appear random and/or asymmetric.
} 
allocative welfare of supermajority is 30.0 , and net welfare of supermajority is 22.1 . To see the performance of various mechanisms, we will check how high their allocative welfare is - in particular, where in the interval between welfare levels of simple majority 25.7 and of first best 30.2 it falls. We will also be interested in waiting costs.

Our three feedback treatments are as follows.

Simple Feedback (SF): All the elements are the same as in No Feedback benchmark, except that the participants are told the evolution of support during the game. In particular, at the beginning of the game, committee members receive a message whether they belong to the minority group of one voter or a majority group of two voters. Also, during the game, as soon as one of the majority players exits, the remaining two voters receive the message that this event occurred.

Public Communication (PC): All elements are like in the Simple Feedback treatment, with the following exception: before the game starts, all three players participate in a free-form public (visible by all three voters) cheap-talk communication.

Group Communication (GC): All elements are like in the Simple Feedback treatment, with the following exception: before the game starts, two players in the majority group participate in a free-form cheap-talk communication visible only to them but not to the single player in the minority.

We now turn to the hypotheses that we will check in our experiments. We start with a series of probable, or possible, positive effects that our three feedback treatments may have, then we move on to the main issue of what their combined effect on efficiency could be.

\subsection{Conjectures}

Our preliminary hypothesis compares the theoretical prediction of the supermajority mechanism with the performance of the corresponding mechanism in the lab. Primarily, 
we are interested whether our supermajority mechanism performs better than simple majority in terms of allocative efficiency, as theory predicts. ${ }^{17}$ This is to replicate one of our earlier results in Kwiek et al. (2016) for a different distribution of values.

Conjecture 1. Consider the supermajority mechanism. Allocative welfare is higher than in simple majority; net welfare is lower.

Perhaps the most important question that we ask in this paper is dealing with the effect of pre-play cheap talk communication on cooperation and conflict. Specifically, we expect Public Communication to work towards improving net efficiency and we think that this will be achieved mostly via lowering the committee's waiting cost. The reason is simple, namely, lower waiting cost is something that all voters can agree with, while they fundamentally disagree with regards to the other aspect of efficiency - which allocation should be selected. By contrast, we expect that Group Communication enhances cooperation within the group, which may cause more conflict between groups and, consequently, more waiting than in Public Communication.

Conjecture 2. Effect of Communication on total waiting cost:

\section{Waiting cost in Public Communication is lower than in Simple Feedback.}

2. Waiting cost in Group Communication is higher than in Public Communication.

Our next step is to check whether there is any evidence of asymmetric collapse. We take advantage of one of the defining features of asymmetric collapse equilibria, namely that one side wins with high probability. Specifically, we ask which side is empowered by feedback. Does the majority become more aggressive after voters learn who belongs to which group? Or is it the minority that stays for longer in the waiting game and wins more often than in the No Feedback mechanism? These are empirical questions because theory provides no clear-cut answer here.

\footnotetext{
${ }^{17}$ In Appendix A, we consider an alternative distribution of intensities of preferences, where supermajority allocative welfare is not better than simple majority.
} 
Even if one abstracts from equilibrium concepts, and instead tries to speculate ad hoc as to who is going to be empowered by feedback, one can still argue in favor of both directions. For example, voters who learn at the very beginning of the game that they are in majority may behave more aggressively, because the pivotal voter is the one with a higher value of the two, and thus she is likely to have a higher value than the minority opponent. Higher stakes may translate into a more aggressive behavior, and this may have a strategic effect on the minority player, making her even less aggressive, and so on. There is, however, an opposite argument. In any of the feedback treatments, the player in the minority group learns that she is pivotal, and therefore knows that exiting early will necessarily leave her without her preferred alternative and the associated value. This may convince her to stay in for longer. The reverse is true in the case of players who learn that they are in the majority group because they learn that they are definitely not pivotal. Thus, there are two contradictory possibilities, Conjecture 3(1) and Conjecture $3(2)$ :

\section{Conjecture 3. Minority wins}

1. less often

2. more often

in the Simple Feedback, Public Communication, and Group Communication treatments than in the No Feedback benchmark.

Since the No Feedback benchmark will have around $1 / 3$ of committees won by the minority group, Conjecture 3(1) says that in the other treatments this number will be less than $1 / 3$. The closer this number to zero, the stronger is evidence for asymmetric collapse in favor of the majority. On the other hand, Conjecture 3(2) says that this number should be greater than $1 / 3$. If it becomes close to 1 then we would say that there is asymmetric collapse in favor of minority. However, we do not expect this to go beyond $1 / 2 .^{18}$

\footnotetext{
${ }^{18}$ Our test for asymmetric collapse is focused on the frequency of wins by minority or majority. This is a
} 
Next, we address the question of whether there is any evidence of instant (or at least earlier) exit hypothesis in feedback mechanisms. Obviously, this question can be asked only if asymmetric collapse does not happen. The fraction of committees in which a majority player exits first should be $2 / 3$ in the No Feedback mechanism. If there is any truth to the instant exit hypothesis, this number should be greater in feedback mechanisms.

Conjecture 4. The fraction of committees in which the first player to exit is a member of the majority group is greater in the three feedback mechanisms than in No Feedback.

Another way to measure the instant exit hypothesis is to look at exit times of the majority players. A successful coordination would mean the absolute difference between exit times of two majority voters is higher in feedback committees than in the No Feedback.

Conjecture 5. The absolute difference between exit times of the two majority voters is higher in the three feedback mechanisms than in the No Feedback benchmark.

The other effect that we test is group sorting. Such coordination among the two majority voters may be measured by how often the majority member who exits first in her group has the lower value. Since we expect a monotonic relationship between intensity and exit in the No Feedback benchmark, a decent coordination should occur there. When we consider Simple Feedback, we hypothesize that there may be a strong incentive to exit early by the members of majority, which may contribute to majority voters clustering their exits at zero - that may worsen group sorting in this treatment. Thus, we want to test whether group sorting deteriorates in Simple Feedback relative to No Feedback. However, comparing Simple Feedback with both communication treatments, and especially Group Communication, we think that majority group members may be able to coordinate in the latter as to who is of the lower value and should exit first. Therefore, our group sorting conjecture has two sub-points:

direct test from the definition. One could contemplate waiting times instead - interpreting shorter waiting as evidence of asymmetric collapse. We prefer not to do that as there are alternative interpretations of shorter waiting times, such as cooperation. 
Conjecture 6. Coordination among the two majority voters: how often does the group member who exits first in her group have the lower value?

1. The coordination will deteriorate in Simple Feedback, relative to No Feedback.

2. The coordination will improve in both Communication treatments, relative to Simple Feedback.

\subsection{Procedural details}

We design a between-subject experiment to test our hypotheses. The experimental sessions were conducted at the SSEL laboratory at the University of Southampton, and our subjects were students recruited through ORSEE (Greiner, 2015). Participants from a broader range of academic disciplines were included. The experiment was programmed in z-tree (Fischbacher, 2007). No subject participated in more than one session. Participants were paid an average of $£ 14$ at the end of each session, including a $£ 4$ show-up fee. Sessions lasted around 1.5 hours, including instructions, comprehension exercises and payment time. ${ }^{19}$

The experimental parameters mirror the theoretical model described above. Each session consisted of a series of independent periods. At the beginning of each period, participants were randomly assigned to three-member committees, and within them, to two groups supporting two different alternatives (and randomly re-matched in every round - strangers matching). Each participant received a valuation according to the distribution presented in Figure 1. Next, in all treatments except the No Feedback treatment, participants were informed whether they belonged to a group of two voters or a group of one voter. Then, in both communication treatments, the participants could engage

\footnotetext{
${ }^{19}$ Upon arrival to the laboratory, participants were randomly allocated to a $\mathrm{PC}$ terminal, where they could find the information sheet and consent forms. After collecting the signed consent forms, the instructions with some examples were distributed and read aloud. The experiment started with the completion of four comprehension exercises, where the experimenters were available to individually answer participants' questions. These exercises were designed to assure the comprehension of the experiment by all the participants. Instructions with examples and comprehension exercises for one treatment are provided in the Appendix.
} 


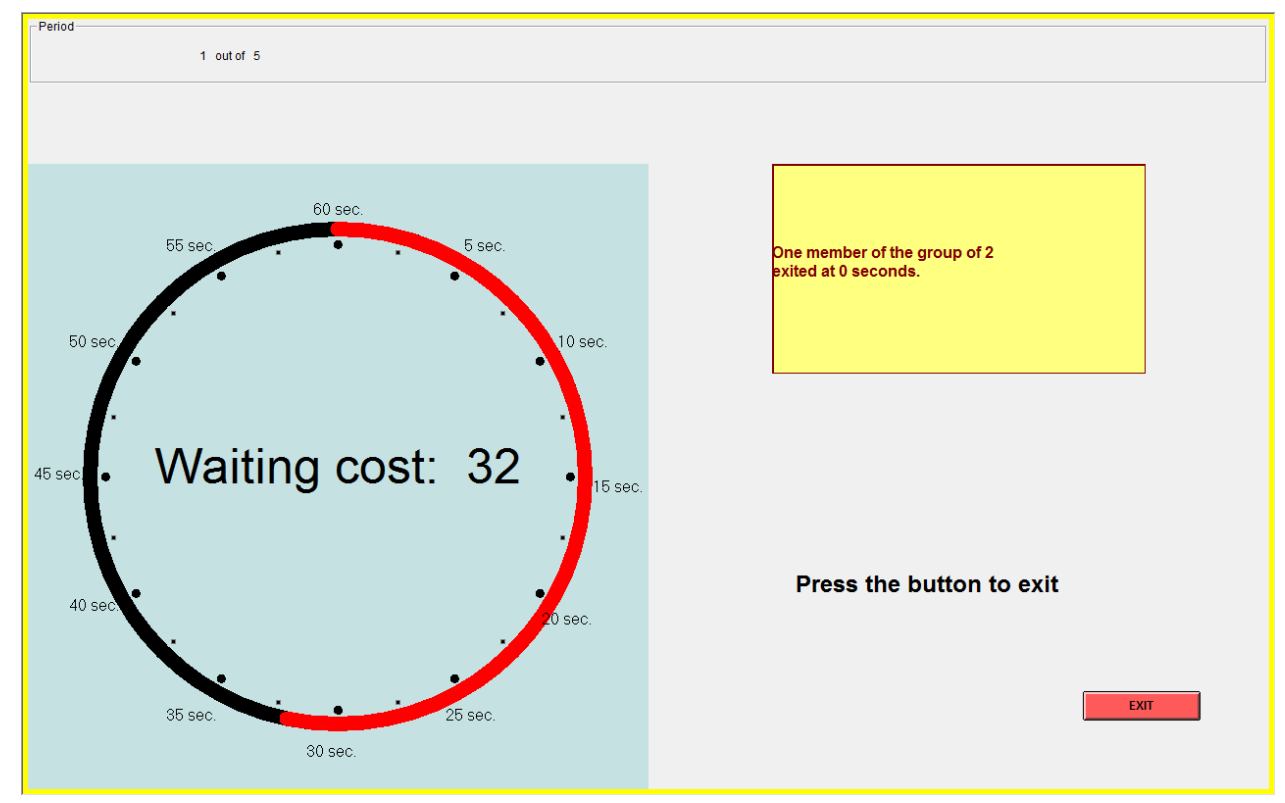

Figure 2: Screen

in a 60-second communication phase, in which they could type any messages via their terminals. In the Group Communication treatment, only two members of the majority group could see the messages; the minority player simply waited for the game to start. After these pieces of information, and after a five-second warning, the true waiting game started. The computer displayed a clock showing how many seconds have elapsed since the beginning of the waiting - seconds represented the accumulated waiting cost in EMUs. The waiting could last for 60 seconds. Figure 2 shows a typical screen of the clock during the decision phase. Each member decided when to cease supporting their preferred alternative. Participants could leave even before the waiting game started (i.e. during the five-second warning). In all treatments involving feedback (SF, PC, and GC) all players received a message when one of the majority voters pressed exit.

At the end of each session, participants drew three random periods and were paid the sum of earnings in these periods, plus a pre-announced endowment. The endowment was given to avoid participants going into negative payoffs which are possible in our game.

One Experimental Monetary Unit (EMU) was equal to 8 pence, and endowment was 120 EMU. The cost of one second of waiting was 1 EMU so the maximum cost of waiting was 60 EMU. 
A total of 207 students participated in 14 sessions. Table 1 describes the number of sessions, periods, number of voters, votes and committee decisions by treatment.

Table 1: Summary of treatments

\begin{tabular}{cccccc}
\hline Treatment & Sessions & Periods/session & $\sharp$ Players & $\sharp$ Votes & $\sharp$ Committees \\
\hline NF & 3 & 40 & 45 & 1800 & 600 \\
SF & 3 & 40 & 42 & 1680 & 560 \\
PC & 4 & $30^{*}$ & 60 & 1950 & 650 \\
GC & 4 & 30 & 60 & 1800 & 600 \\
\hline Total & 14 & & 207 & 7230 & 2410 \\
\hline
\end{tabular}

${ }^{*}$ one session had 40 periods

\section{Results}

Dynamic wars of attrition are games in which discussing results presents one specific difficulty. Namely, intended actions of some players are inherently unobservable. For example, if the minority player exits first, the experimenter will not see when the majority players would exit. ${ }^{20}$ Moreover, our game is of incomplete information, in which full strategies would not be observable even if the game was static. For this reason, we first show the aggregate efficiency performance of the four mechanisms that we study, and then we proceed to identify various differences.

\subsection{Overview of welfare performance}

Table 2 shows the summary of allocative and net welfare and the associated waiting cost, by treatment at the committee level. For comparison, it also shows welfare that would be realized under simple majority, the first best and the total sum of voters' valuations in a committee. The first row shows the theoretical prediction for the No Feedback mechanism.

Figure 3 is an alternative way to present some of these results. Allocative welfare of each treatment is measured on the horizontal axis and the waiting cost is on the vertical

\footnotetext{
${ }^{20}$ In a preliminary study (Kwiek et al. 2016), we compare static and dynamic versions of this game and we observe that the behavior in these two versions is different.
} 
Table 2: Welfare

\begin{tabular}{cccccccc}
\hline Treatment & $\begin{array}{c}\text { Allocative } \\
\text { Welfare }\end{array}$ & $\begin{array}{c}\text { Net } \\
\text { Welfare }\end{array}$ & $\begin{array}{c}\text { Waiting cost } \\
\text { per committee }\end{array}$ & $\begin{array}{c}\text { Simple } \\
\text { Majority }\end{array}$ & $\begin{array}{c}\text { First } \\
\text { Best }\end{array}$ & $\begin{array}{c}\text { Sum of } \\
\text { Values }\end{array}$ & $\begin{array}{c}\text { Number } \\
\text { of Obs. }\end{array}$ \\
\hline NF(th) & 30.0 & 22.3 & 7.7 & 25.7 & 30.2 & 38.5 & \\
NF & 27.4 & 20.2 & 7.3 & 25.5 & 29.6 & 37.1 & 600 \\
& $(22.3)$ & $(23.1)$ & $(14.3)$ & $(22.6)$ & $(21.8)$ & $(26.3)$ & \\
SF & 26.2 & 16.5 & 9.8 & 24.1 & 29.5 & 37.5 & 560 \\
& $(20.0)$ & $(24.8)$ & $(19.5)$ & $(20.0)$ & $(19.7)$ & $(25.0)$ & \\
PC & 27.4 & 20.9 & 6.5 & 25.7 & 30.2 & 38.7 & 650 \\
& $(20.3)$ & $(24.9)$ & $(17.8)$ & $(21.1)$ & $(20.2)$ & $(26.0)$ & \\
GC & 28.4 & 19.5 & 8.9 & 24.8 & 30.2 & 38.0 & 600 \\
& $(21.0)$ & $(25.8)$ & $(19.3)$ & $(21.7)$ & $(20.8)$ & $(25.3)$ & \\
\hline
\end{tabular}

Entries are averages at committee level with standard deviations in parentheses.

Allocative welfare is defined as the sum of valuations of the winning group.

The first row reports the theoretical prediction for the No Feedback mechanism.

axis. Thus, the lines of the unit slope indicate points of exactly the same net welfare, with net welfare increasing towards south-east. The four light-shaded points represent experimental results, and the black point represents the theoretical prediction of the No Feedback committee. All values are expressed as the fraction of the average sum of values in that treatment.

We can see in Table 2 that the allocative efficiency of the supermajority is greater than simple majority in all treatments. The same fact can be observed in Figure 3 once we realize that the simple majority score is $2 / 3$ of the sum of values measured on the horizontal axis - all points that represent treatments are to the right of $0.67 .^{21}$

Moving to a formal test of the hypothesis that the distribution of allocative efficiency under supermajority and simple majority is the same, we apply the Wilcoxon matchedpairs signed-rank test employing the statistically independent sessions as the unit of observation to conclude that this hypothesis can be rejected ( $\mathrm{p}$-value $=0.001$ ). Thus, we do find support for Conjecture 1.

Next, we recast these welfare comparisons in a panel regression framework using individual subject random effects and standard errors clustered at the session level. ${ }^{22}$

\footnotetext{
${ }^{21}$ The welfare point corresponding to simple majority is 0.66 on the horizontal axis and zero on the vertical axis, which is outside of its range.

${ }^{22}$ Clustering standard errors at the individual level does not change the overall conclusion. Likewise,
} 


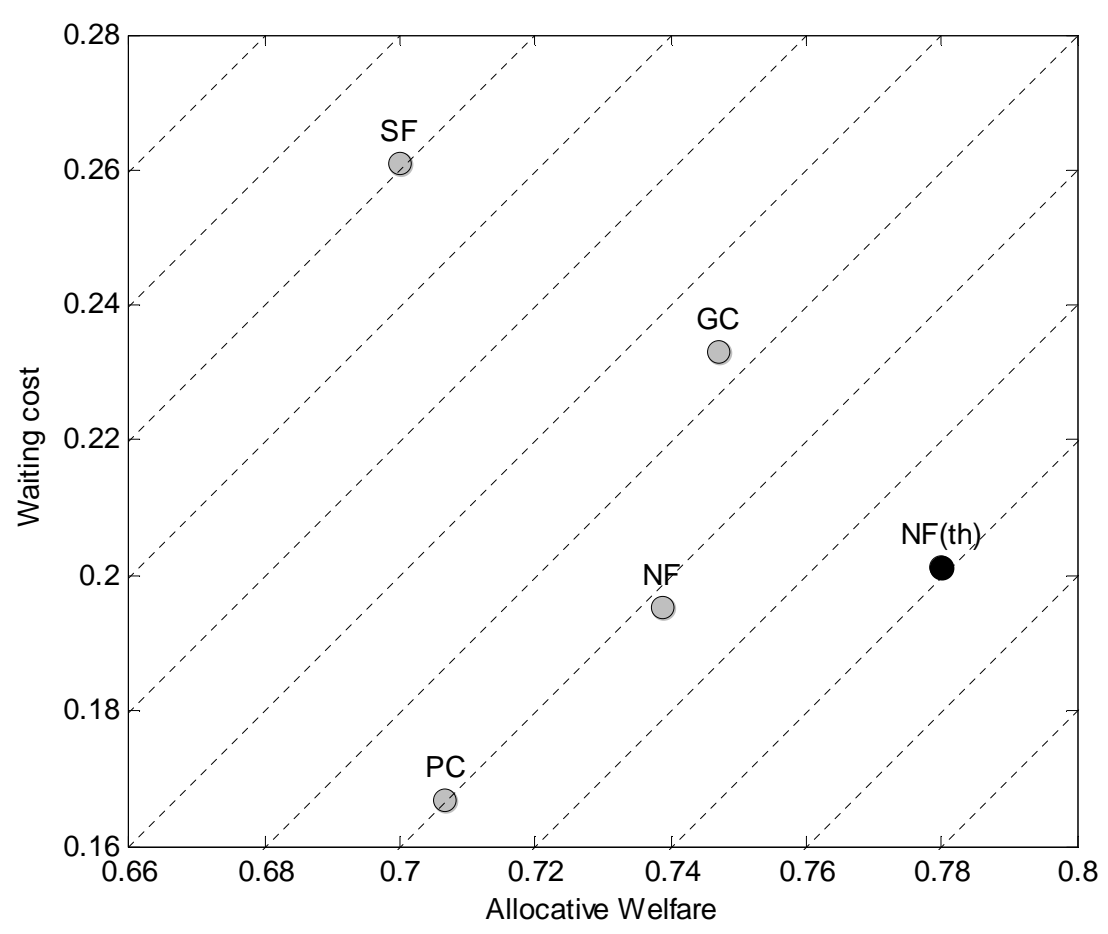

Figure 3: Allocative welfare vs waiting cost (by treatment, \% of Sum of Values). Diagonal lines depict combinations of constant net welfare.

The results are presented in Table 3. Note that Simple Feedback is not statistically distinguishable from Public Communication with regards to allocative efficiency, whereas there is a statistically significant difference between Public Communication and Group Communication. $^{23}$

As far as waiting cost alone is concerned, reported in columns 3-4 of Table 3, we find that Simple Feedback is associated with significantly higher waiting cost than No Feedback, Public Communication is associated with lower waiting cost than Simple Feedback (p-value of test is 0.01 and 0.002 in columns 3 and 4, respectively) and Group Communication (p-value of test is 0.03 and 0.04 in columns 3 and 4, respectively).

Altogether, we can state one of the headline results of this paper as follows. The allocative efficiency outcome depends on the type of communication. When only members of one group can communicate with each other (Group Communication), then the conflict estimating a mixed-effects model with subject and session random effects yields similar conclusions.

${ }^{23}$ The p-values of the F-test comparing SF to PC in columns 1 and 2 are 0.91 and 0.66 ; the ones comparing $\mathrm{PC}$ to GC are 0.0004 and 0.0001. 
Table 3: Regression analysis of allocative welfare and waiting cost. All columns report random effects regressions, with the individual as the unit of observation.

\begin{tabular}{ccccc}
\hline Dep variable: & \multicolumn{2}{l}{ Allocative Efficiency } & \multicolumn{2}{c}{ Waiting Cost } \\
\hline Constant & $-1.35^{* * *}$ & & $0.41^{*}$ & \\
& $(0.15)$ & & $(0.23)$ & \\
SF & $-0.50^{* * *}$ & $-0.50^{* * *}$ & $0.81^{* *}$ & $0.81^{* *}$ \\
& $(0.16)$ & $(0.16)$ & $(0.40)$ & $(0.41)$ \\
PC & $-0.48^{* *}$ & $-0.43^{* *}$ & -0.36 & -0.48 \\
& $(0.19)$ & $(0.17)$ & $(0.36)$ & $(0.84)$ \\
GC & 0.08 & 0.14 & 0.47 & 0.30 \\
& $(0.16)$ & $(0.15)$ & $(0.33)$ & $(0.34)$ \\
Valuation & $0.85^{* * *}$ & $0.85^{* * *}$ & $0.16^{* * *}$ & $0.16^{* * *}$ \\
& $(0.01)$ & $(0.01)$ & $(0.01)$ & $(0.01)$ \\
Period Dummies & No & Yes & No & Yes \\
\hline & \multicolumn{5}{c}{7230} \\
\hline
\end{tabular}

Standard errors clustered at the session level, in parentheses. $* / * * / * * *$ indicate significance at the 0.10/0.05/0.01 level.

between the groups, as measured by waiting time, is high, but also the mechanism is able to select the correct alternative more often. By allowing the groups to participate in joint communication (Public Communication), we change the spirit of cooperation. Instead of contributing to the conflict between the groups, this kind of communication works towards diminishing it and preventing delay. However, the price to pay for this gain is that the allocative performance of this mechanism is poorer. This is an important consideration for a mechanism designer who is interested in allocative welfare and does not care about waiting time.

The analysis below will try to dissect these main results to identify potential sources of the differences between the treatments.

\subsection{Asymmetric collapse hypothesis}

First, we want to see what is the overall effect of treatments on the likelihood of winning by group. That is, we want to establish which of the two contradictory possibilities - Conjecture 3(1) or Conjecture 3(2) - is consistent with the experimental findings. 
The direct indication that Conjecture 3(2) is correct comes from Table 4, which presents the percentage of committees in which the majority and the minority group won for each treatment. Note that the wins by majority are split between wins that were achieved because the minority voter dropped out first and those that were won when the minority voter dropped out after one of the majority voters had already left.

Table 4: Incidence of winning by group.

\begin{tabular}{ccccc}
\hline Treatment & $\begin{array}{c}\text { Majority } \\
\text { (minority exit first) }\end{array}$ & $\begin{array}{c}\text { Majority } \\
\text { (majority exit first) }\end{array}$ & Minority & $\begin{array}{c}\text { Number } \\
\text { of Obs. }\end{array}$ \\
\hline NF & 33.0 & 34.2 & 32.8 & 600 \\
SF & 28.9 & 30.4 & 40.7 & 560 \\
PC & 37.7 & 23.7 & 38.6 & 650 \\
GC & 28.0 & 35.3 & 36.7 & 600 \\
\hline
\end{tabular}

All entries are in $\%$.

We see that each of three winning-by-group categories occurs on average $1 / 3$ of times in the No Feedback benchmark. Given the anonymity underpinning the No Feedback mechanism it is almost impossible that this number were different, other than by pure chance. The interesting results are in the remaining three feedback treatments - in all of them the minority wins more often than $1 / 3$ of times. ${ }^{24}$ The effect is the strongest for Simple Feedback. This supports Conjecture 3(2) and goes against Conjecture 3(1).

\subsection{Instant exit hypothesis}

The fact that there is no evidence of asymmetric collapse enables us to test other hypotheses. The next step is to report what the experiments imply about instant exit.

The first column of Table 5 shows how often the player who exits first is a member of majority, and thus a non-pivotal player (this is equal to $100 \%$ minus the first column of Table 4). As expected, in the No Feedback treatment, a member of the majority exits first in around $2 / 3$ of all committees. We see that this fraction is slightly higher in Simple Feedback and in Group Communication, but is lower in Public Communincation. Testing

\footnotetext{
${ }^{24} \mathrm{~A}$ Wilcoxon test that the fraction of minority wins in the 11 sessions for treatments $\mathrm{SF}, \mathrm{PC}$ and GC is $1 / 3$ yields a p-value equal to 0.013 .
} 
equality taking the session as the unit of independent observation using a Mann-Whitney test suggests that the difference between No Feedback and the three feedback treatments combined is not significant ( $\mathrm{p}$-value $=0.43$ ), we thus do not find support for Conjecture 4. We do not conduct pairwise tests of the three treatments against NF, because of the few statistically independent observations.

Table 5: Instant exit hypothesis.

\begin{tabular}{ccc}
\hline Treatment & $\begin{array}{c}\text { \% of committees in } \\
\text { which 1st player to exit is } \\
\text { a member of the majority }\end{array}$ & $\begin{array}{c}\text { Absolute difference in exit } \\
\text { time between two majority } \\
\text { voters (in seconds) } \ddagger\end{array}$ \\
\hline NF & 67.0 & 3.6 \\
& 71.1 & $(6.45)$ \\
SF & 62.3 & 4.4 \\
& & $(7.52)$ \\
PC & 72.0 & 2.6 \\
& & $(5.25)$ \\
GC & & 5.2 \\
& & $(9.55)$ \\
\hline
\end{tabular}

Standard deviations in parentheses.

$\ddagger$ This is calculated only for committees that are won by the minority.

There are 197, 228, 251 and 220 such committees for NF, SF, PC and GC, respectively.

The second column of Table 5 looks at the difference in exit times between two majority voters. As stated in Conjecture 5, we expect that this difference will increase in feedback committees relative to No Feedback. This difference is 3.6 seconds in the No Feedback benchmark. It increases in Simple Feedback and Group Communication treatments, providing evidence in favor of Conjecture 5. However, the Public Communication treatment is again the odd one out; this difference in exit times is lower than in No Feedback benchmark and definitely lower than in Group Communication.

\subsection{Group sorting hypothesis}

We next examine Conjecture 6 that deals with group sorting. We calculate how often the first member of majority to exit has a strictly higher valuation. ${ }^{25}$ We call this fraction

\footnotetext{
${ }^{25}$ We calculate this fraction only for committees for which the first voter to exit is a member of majority.
} 
a group sorting miscoordination and report these values in Table 6. The first column reports the fraction of all identifiable committees that miscoordinate this way, while the second column shows only the fraction of committees for which this miscoordination is relatively high, in this case, it is 6 or higher.

Table 6: Group sorting hypothesis.

\begin{tabular}{ccc}
\hline Treatment & $\begin{array}{c}\text { Group sorting miscoordination } \\
\text { (difference in values } 1 \text { or higher) }\end{array}$ & $\begin{array}{c}\text { Group sorting miscoordination } \\
\text { (difference in values 6 or higher) }\end{array}$ \\
\hline NF & 14.7 & 6.2 \\
SF & 13.3 & 6.8 \\
PC & 11.4 & 5.7 \\
GC & 4.4 & 1.6
\end{tabular}

All entries are in \%.

We see that the majority voters decide who exits first not in a completely random fashion - the numbers in the first column are much lower than 50\%. Group sorting does not seem to change when members of majority learn that they are members of majority (Simple Feedback); we can reject the claim in point 1 of Conjecture 6, as there is no evidence of players racing to exit and trying to preempt their opponent, affecting sorting in a negative way. Public Communication does not seem to change the group sorting by a lot; in this case, we reject point 2 of Conjecture 6 . On the other hand, Group Communication does seem to improve group sorting, providing evidence in favor of point 2 of Conjecture 6 .

\subsection{Sources of misallocation}

Questions investigated up to now are relevant for allocative efficiency. Now, we zoom in on this issue directly. Define misallocation to be an event whereby a group fails to win their alternative when they should win it, according to the allocative welfare criterion. We want to check how often and when misallocations occur.

We split committees into those in which the minority should win or the majority should win, in allocative efficiency terms; we call them minority win and majority win 
committees, respectively. The bars in Figure 4 indicated by "1+" show how often misallocation occurs in minority and majority win committees, by treatment.

What we see is one consequence of Conjecture 3(2) that feedback empowers the minority. Introducing feedback seems to shift the misallocation: it is lower in minority win committees, and higher in majority win committees, relative to No Feedback. The fact that misallocation in minority win committees goes down after introducing feedback is good news for allocative efficiency. However, the bad news is that in those committees in which majority should win, the feedback increases the incidence of minority winning. This shift seems to be higher in Simple Feedback and in Public Communication, but not as big in Group Communication. In any case, we cannot see from case "1+" if any of the three feedback treatments beat the No Feedback benchmark overall, and so we still do not know what the source of inefficiencies is.

Looking at all instances of misallocation is rough in the sense that this method treats all errors in the same way, regardless of how costly in allocative welfare terms they are. We will now try to account for the magnitude of the associated welfare loss. Case two in Figure 4, denoted " $6+$ ", counts only the events in which the welfare cost of misallocation is 6 or larger, thus ignoring the misallocation cases in which the welfare cost is small, between 1 and 5 . Likewise, the final case, denoted " $11+$ ", includes only cases in which the allocative welfare cost of misallocation is 11 or higher.

The conclusion that emerges from cases " $6+$ " and " $11+$ " is somewhat more subtle than in case " $1+$ ". When we compare Simple Feedback and Public Communication with the No Feedback benchmark then we see that there is the previously identified shift: both of these feedback treatments create less misallocation when minority should win, and more misallocation when majority should win. The Group Communication feedback treatment, on the other hand, is different. When minority should win, Group Communication limits the misallocation relative to No Feedback exactly like Simple Feedback and Public Communication, although not to such a great extent. However, when the majority group should win, Group Communication does not admit more misallocation 

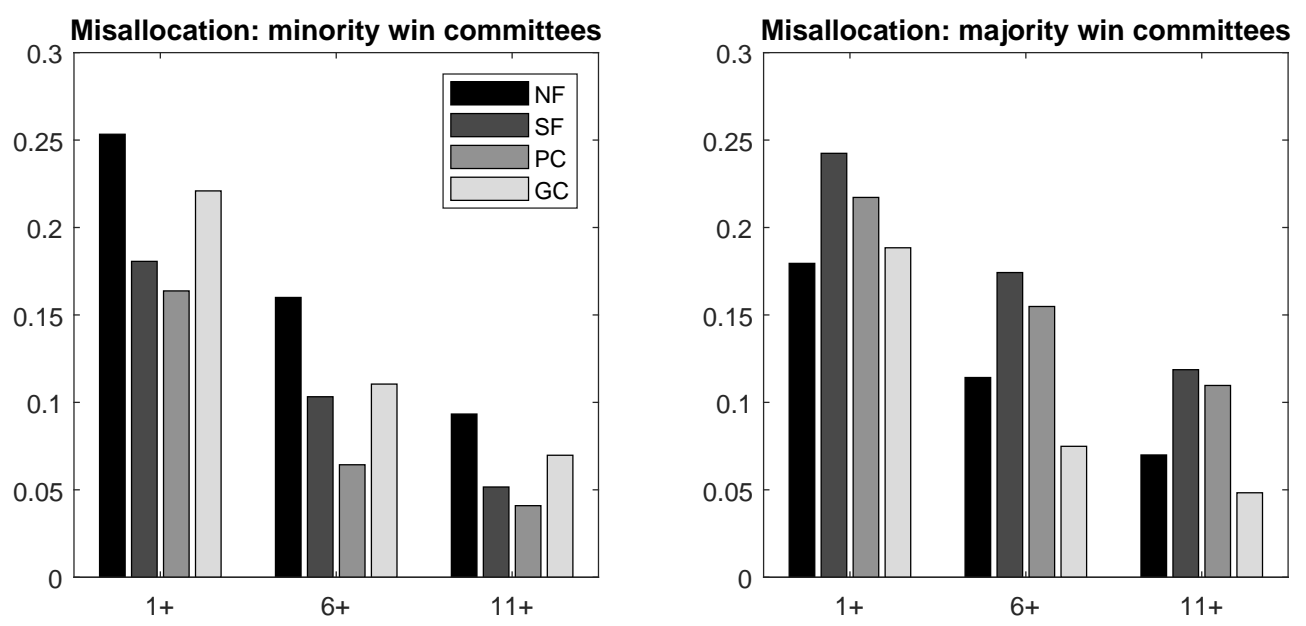

Figure 4: Misallocation by group

like the other two feedback treatments do. If anything, this treatment leads to even less misallocation than No Feedback for misallocations that matter ("6+" and " $11+$ "), the fact that was not clear in case " $1+$ ". Hence, Group Communication does better than No Feedback in both cases - when majority should win and when minority should win.

Figure 4 seems to provide a good explanation of the overall allocative welfare performance of our treatments presented earlier in Table 2 and Figure 3. The fact that Simple Feedback and Public Communication perform poorly in terms of allocative welfare is consistent with Figure 4 in the following sense. Since the panel on the right represents the cases that occur more often, the welfare loss associated with more frequent misallocation dominates the welfare gain associated with less frequent misallocation on the left panel. Group Communication, on the other hand, beats the No Feedback benchmark on both accounts and thus leads to the best allocative welfare of all four mechanisms.

To confirm these results in a regression framework, we verify how treatments affect welfare separately for minority and majority win committees in Table 7 . What we see is that in majority win committees allocative welfare is lower and statistically different in Simple Feedback and Public Communication relative to No Feedback. On the other hand, in minority win committees allocative welfare is higher in those treatments, albeit not in a statistically significant way. Furthermore, Group Communication is not statistically 
Table 7: Regression results: minority versus majority win committees

\begin{tabular}{ccccc}
\hline Dep variable: & \multicolumn{2}{c}{ Allocative welfare } & \multicolumn{2}{c}{ Waiting Cost } \\
& minority win & majority win & minority win & majority win \\
\hline Constant & $-2.52^{* * *}$ & $-0.96^{* * *}$ & $1.09^{* * *}$ & 0.26 \\
SF & $(0.31)$ & $(0.21)$ & $(0.22)$ & $(0.25)$ \\
& 0.27 & $-0.76^{* * *}$ & 0.60 & $0.72^{* *}$ \\
PC & $(0.53)$ & $(0.13)$ & $(0.72)$ & $(0.31)$ \\
& 0.08 & $-0.73^{* * *}$ & $-1.16^{* *}$ & -0.09 \\
GC & $(0.34)$ & $(0.23)$ & $(0.49)$ & $(0.39)$ \\
Sum of Valuations & 0.25 & 0.06 & 0.21 & $0.53^{*}$ \\
& $(0.40)$ & $(0.13)$ & $(0.50)$ & $(0.31)$ \\
& $0.86^{* * *}$ & $0.85^{* * *}$ & $0.15^{* * *}$ & $0.16^{* * *}$ \\
\hline$N$ & $(0.03)$ & $(0.02)$ & $(0.02)$ & $(0.01)$ \\
\hline
\end{tabular}

All columns report random effects regressions, with the individual as the unit of observation. Standard errors clustered at the session level, in parentheses. $* / * * / * * *$ indicate significance at the $0.10 / 0.05 / 0.01$ level.

distinguishable from No Feedback in both minority and majority win committees. ${ }^{26}$

\section{Textual analysis of communication}

Since the communication treatment chats are conducted via computer terminals, we can record and analyze them. The objective is to see if the nature of communication changes between treatments in a way that fits the narrative that we offered above.

We identify 15 categories of statements that may occur in a conversation. Assignment of chat lines into these categories was carried out on a random sample of committees by two independent research assistants.

Table 8 contains the results expressed in two ways. ${ }^{27}$ The first three columns show how many times a message line of a particular category occurs, per committee and per participant. For instance, a majority voter's line assigned as "Report actual value" was sent 0.54 times per committee in the Public Communication treatment. In contrast, this

\footnotetext{
${ }^{26}$ Waiting cost is not our main concern here, but, for completeness, we do provide its analysis in Table 7. We see that waiting cost goes up in SF relative to NF mostly via majority win committees. Likewise, waiting time goes down in $\mathrm{PC}$ mostly via minority win committees.

${ }^{27}$ The count that we report in Table 8 is the average of two assessments, but we checked that none of the significant results below depend on which research assistant is selected.
} 
number goes up to 0.88 in the Group Communication treatment.

Table 8: Occurrence of statements by category.

\begin{tabular}{|c|c|c|c|c|c|c|}
\hline & \multicolumn{3}{|c|}{$\begin{array}{l}\text { Number of messages } \\
\text { per committee, per player }\end{array}$} & \multicolumn{3}{|c|}{$\begin{array}{l}\text { Fraction of committees } \\
\text { with this message }\end{array}$} \\
\hline & \multicolumn{2}{|c|}{$\mathrm{PC}$} & \multirow{2}{*}{$\begin{array}{c}\text { GC } \\
\text { Majority }\end{array}$} & \multicolumn{2}{|c|}{$\mathrm{PC}$} & \multirow{2}{*}{$\begin{array}{c}\text { GC } \\
\text { Majority }\end{array}$} \\
\hline & Minority & Majority & & Minority & Majority & \\
\hline Irrelevant & 0.81 & 0.9 & 0.85 & $46 \%$ & $72 \%$ & $64 \%$ \\
\hline Report actual value & 0.54 & 0.54 & 0.88 & $54 \%$ & $63 \%$ & $91 \%^{\dagger}$ \\
\hline Report "high" & 0.07 & 0.07 & 0.02 & $6 \%$ & $12 \%$ & $4 \%^{\dagger}$ \\
\hline Report "low" & 0.07 & 0.07 & 0.04 & $7 \%$ & $11 \%$ & $7 \%$ \\
\hline Asking for values, strategy & 0.15 & 0.19 & 0.32 & $13 \%$ & $28 \%$ & $46 \%^{\dagger}$ \\
\hline Own immediate exit & 0.26 & 0.17 & 0.26 & $24 \%$ & $27 \%$ & $45 \% \dagger$ \\
\hline Suggesting immediate exit & 0.08 & 0.16 & 0.14 & $7 \%$ & $26 \%$ & $25 \%$ \\
\hline Own staying & 0.03 & 0.04 & 0.15 & $3 \%$ & $6 \%$ & $28 \%^{\dagger}$ \\
\hline Suggesting staying & 0.03 & 0.03 & 0.07 & $3 \%$ & $4 \%$ & $13 \%^{\dagger}$ \\
\hline Other strategy & 0.1 & 0.13 & 0.38 & $9 \%$ & $19 \%$ & $51 \%^{\dagger}$ \\
\hline Agreement w/ strategy & 0.15 & 0.22 & 0.44 & $14 \%$ & $32 \%$ & $64 \%^{\dagger}$ \\
\hline Disagreement w/ strategy & 0.03 & 0.02 & 0.01 & $2 \%$ & $5 \%$ & $2 \%$ \\
\hline Game history & 0.04 & 0.07 & 0.03 & $3 \%$ & $9 \%$ & $4 \%$ \\
\hline General but relevant & 0.68 & 0.66 & 0.51 & $38 \%$ & $59 \%$ & $48 \%$ \\
\hline Minority or majority ref & 0.13 & 0.28 & 0 & $11 \%$ & $41 \%$ & $1 \%^{\dagger}$ \\
\hline
\end{tabular}

Sample: 216 committees in PC, 199 in GC. Average of two RAs.

†Significantly different from column "PC Majority" at 5\% significance for both RAs.

The last three columns show the fraction of committees in which a given category of message was sent. For instance, a majority player sent a message that was categorized as "Report actual value" in $63 \%$ committees in the Public Communication treatment. In the Group Communication treatment, $91 \%$ of committees had this type of message.

We can directly compare how the majority voters communicated in both Communication treatments. We see that the nature of communication changed and the direction of this change is quite one-sided. It seems that in Group Communication, majority voters are inclined to share their information and discuss their joint strategies more than in Public Communication. For example, messages categorized as "Report actual value" occur more often, while those categorized in broader terms, as only "low" or "high", occur less often. Likewise, messages asking "for values and strategy", indicating "own immediate exit", "own immediate stay", "suggest staying", or talking about "other strategy" 28 oc-

\footnotetext{
${ }^{28}$ Research assistants assigned in the category "other strategy" messages that referred to strategy in
} 
cur significantly more often in Group than in Public Communication. All this suggests a better coordination and cooperation among majority members in Group Communication, corroborating our earlier interpretation.

\section{Conclusions}

We report results from a series of experiments that examine the joint impact of feedback and pre-voting communication on voting outcomes in supermajority committees. We obtain a series of results. In line with theoretical predictions, the committee with a stringent supermajority requirement performs better in allocative efficiency terms than theoretical simple majority when heterogeneity of preference intensities is high (and not as good when heterogeneity of preference intensities is low, as shown in Appendix A). This corroborates our earlier analysis in Kwiek et al. (2016), where, among other things, we studied a mechanism similar to the No Feedback benchmark, although with a simpler binary distribution of values. The current paper confirms this observation in more realistic mechanisms with feedback and communication. Moreover, it finds systematic differences between feedback, public and within group communication.

Specifically, revealing their majority-minority status makes the minority (pivotal) voter win more often. Pre-play communication among all committee members (PC) shortens the waiting time and thus improves the net efficiency performance of committee decisions, but the effect on allocative efficiency is not significant relative to Simple Feedback and it is worse than in No Feedback. Within-group communication (GC) also improves net efficiency but in a completely different way. Allocative efficiency is better than in Simple Feedback, but waiting cost is not as low as in Public Communication.

Thus, as far as positive analysis is concerned, the paper sheds light on equilibrium selection problem in our multiplayer war of attrition, and, as far as normative questions are concerned, it highlights the efficiency-enhancing but subtle role of communication.

some way but were not obviously assignable to one of the other categories. These could be, for instance, conditional proposals. 
Some important extensions can be considered. In these concluding remarks, we want to address two kinds - the number of voters and waiting cost.

There is a difference if the two opposing sides of a war of attrition are single players or coalitions of players. To our knowledge, ours is the first experimental study of the latter case, although our example is minimal - there are only three players, two of which form a single coalition. Thus, we are able to address issues like asymmetry induced by the size of the majority, the associated possibility of asymmetric collapse, instant exit, and group sorting. All these potential effects come into focus when we differentiate treatments by communication protocol. Increasing the size of the committee, both through more numerous coalitions and having coalitions on both sides of the conflict rather just on one, can lead to an interesting study, but we conjecture that it will not invalidate the direction of our basic results.

In this paper, we assumed that individual voters avoid paying cost of waiting after they yielded, even if the final decision was not reached by the committee yet, and waiting continued. We call this an individual cost assumption. However, many real-life committees require all participants to stay engaged until the final decision is made. We call this a common cost assumption, as all voters pay the same cost of waiting no matter what the profile of exits was. ${ }^{29}$ We believe that studying committees with common costs would be very useful. The incentives under the common cost assumption are somewhat different from the one studied in this paper. It is not just the fact that the average waiting cost is likely to be mechanistically greater, as even relatively indifferent participants are forced to wait, but that this rule may have strategic effects. Namely, instant exit does not seem to be that advantageous as in the case of individual cost. One could claim (naïvely) that the common cost rule would make the majority win more often. Theoretical equilibrium of this mechanism and its experimental verification are subjects of ongoing work.

\footnotetext{
${ }^{29}$ In the terminology of Bulow and Klemperer (1999), our individual cost assumption corresponds to "standards" type, while the common cost to "oligopoly" type of generalized war of attrition, although this terminology does not necessarily fit our context.
} 


\section{References}

Baron, David, P., T. Renee Bowen, Salvatore Nunnari, (2017), "Durable Coalitions and Communication: Public versus Private Negotiations", Journal of Public Economics, Vol. 156, pp. 1-13.

Baumgartner, Frederic J., (2003), Behind Locked Doors: A History of the Papal Elections. Palgrave Macmillan, New York.

Bawn, Kathleen and Gregory Koger, (2008), "Effort, Intensity and Position Taking: Reconsidering Obstruction in the Pre-Cloture Senate", Journal of Theoretical Politics, 20(1): pp. 67-92.

Bulow, J., and P. D. Klemperer, (1999), "The Generalized War of Attrition," American Economic Review, Vol. 89, No. 1, pp. 175-89.

Brookins, P., Lightle, adJ.P. and Ryvkin, D. (2018), "Sorting and communication in weak-link group contests," Journal of Economic Behavior and Organization, Vol. 152, pp. 64-80.

Casella, Alessandra, (2005), "Storable Votes", Games and Economic Behavior, Vol. 51, pp. 391-419.

Cason, T.N., Sheremeta, R.M. and Zhang, J., (2012), "Communication and efficiency in competitive coordination games," Games and Economic Behavior, Vol. 76, pp. $26-43$.

Cason, T.N., Sheremeta, R.M. and Zhang, J., (2017), "Asymmetric and endogenous communication in competition between groups," Experimental Economics, Vol. 20, pp. 946-972.

Clarke, E., (1971), "Multipart Pricing of Public Goods", Public Choice, Vol. 11, No. 1, pp. 17-33. 
Dechenaux Emmanuel, Dan Kovenock \& Roman Sheremeta, (2015), "A Survey of Experimental Research on Contests, All-pay Auctions and Tournaments," Experimental Economics, Springer, Vol. 18, No. 4, 609-669.

Dion, Douglas, Frederick J. Boehmke, William MacMillan, Charles R. Shipan, (2018), "The Filibuster as a War of Attrition", Journal of Law and Economics, vol. 59, pp. $569-595$.

Fischbacher, Urs, (2007), "z-Tree: Zurich Toolbox for Ready-Made Economic Experiments", Experimental Economics, Vol. 10, pp. 171-8.

Fudenberg, D, and J. Tirole, (1996), Game Theory. The MIT Press, Cambridge, Massachusetts.

Goeree, J.K. and L. Yariv, (2011), "An Experimental Study of Collective Deliberation", Econometrica, Vol. 79, No. 3, pp. 893-921.

Greiner, Ben, (2015), "Subject Pool Recruitment Procedures: Organizing Experiments with ORSEE", Journal of the Economic Science Association, Vol 1, Issue 1, pp. $114-125$.

Grosser, J. K. and A. Schram, (2006), "Neighborhood Information Exchange and Voter Participation: An Experimental Study", American Political Science Review, Vol 100, No 2, pp. 235-48.

Groves, Theodore, (1973), "Incentives in Teams", Econometrica, Vol. 41, No. 4, pp. $617-631$.

Hörisch H. and O. Kirchkamp, (2010), "Less Fighting than Expected-Experiments with War of Attrition and All-pay Auctions", Public Choice, Vol. 144, No. 1, pp. $347-367$.

Hortala-Vallve, Rafael and Aniol Llorente-Saguer, (2010), "A Simple Mechanism for Resolving Conflict", Games and Economic Behavior, Vol. 70, pp. 375-91. 
Jackson, Matthew O. and Hugo F Sonnenschein, (2007), "Overcoming Incentive Constraints by Linking Decisions", Econometrica, Vol. 75, No. 1, pp. 241-257.

Kittel B., and W. Luhan, and R. Morton, (2014), "Communication and Voting in Multi-party Elections: An Experimental Study", Economic Journal, Vol. 124, No. 574, pp. 196-225.

Krishna, Vijay, John Morgan, (1997), "An Analysis of the War of Attrition and the All-Pay Auction", Journal of Economic Theory, Vol. 72.

Kwiek, M., (2014), "Conclave", European Economic Review, Vol. 70, Issue C, pp. $258-275$.

Kwiek, M., (2017), "Efficient Voting with Penalties", Games and Economic Behavior, Vol. 104, pp. 468-485.

Kwiek, M., H. Marreiros and M. Vlassopoulos, (2016), "An Experimental Study of Voting with Costly Delay", Economics Letters, Vol. 160, Issue C, pp. 23-26.

Leibbrandt, A. and Sääksvuori, L., (2012), "Communication in intergroup conflicts," European Economic Review, Vol. 56, pp. 1136-1147.

Martinelli, César, and Thomas R. Palfrey, (2017), "Communication and Information in Games of Collective Decision: A Survey of Experimental Results", George Mason University Interdisciplinary Center for Economic Science, Paper No. 18-01.

Matthews, Steven A., (1989), "Veto Threats: Rhetoric in a Bargaining Game", The Quarterly Journal of Economics, Vol. 104, No. 2, pp. 347-369.

Matthews, Steven A., and Andrew Postlewaite, (1989), "Pre-play Communication in Two-Player Sealed-Bid Double Auction", Journal of Economic Theory, Vol. 48, pp. $238-263$.

McAfee, R.P. and J. McMillan, (1992), "Bidding Rings", American Economic Review, Vol. 82, No. 3, pp. 579-599. 
Myatt, David P., (2005), "Instant Exit From the Asymmetric War Of Attrition", Department of Economics Discussion Paper series, University of Oxford, No. 160.

Myerson, R.B., (1981), "Optimal Auction Design", Mathematics of Operations Research, Vol. 6, No. 1, pp. 58-73.

Nalebuff, Barry and John Riley, (1985), "Asymmetric Equilibria in the War of Attrition", Journal of Theoretical Biology, Vol. 113, pp. 517-527.

Oprea, Ryan, Bart Wilson and Arthur Zillante, (2013), "War Of Attrition: Evidence From A Laboratory Experiment On Market Exit", Economic Inquiry, Vol. 51. No 4, pp. 2018-2027.

Palfrey, Thomas R., (2016), "Experiments in Political Economy", in: John H. Kagel and Alvin E. Roth, (eds.). The Handbook of Experimental Economics, Volume 2, Princeton University Press.

Palfrey, Thomas R. and Kirill Pogorelskiy, (2017), "Communication Among Voters Benefits the Majority Party", Economic Journal, forthcoming, available at https://doi.org/10.1111/ec

Pogorelskiy, Kirill, (2014), "Correlated Equilibria in Voter Turnout Games", APSA 2014 Annual Meeting Paper. Available at https://ssrn.com/abstract=2451740

Ponsati, Clara and Jozsef Sakovics, (1996), "Multiperson Bargaining over Two Alternatives", Games and Economic Behavior, Vol. 12, No. 2, pp. 226-244.

Rapoport, A. and Bornstein, G., (1989), "Solving public goods problems in competition between equal and unequal size groups," Journal of Conflict Resolution, Vol. 33, pp. 460-479.

Smith, J. Maynard, (1974), "The Theory of Games and the Evolution of Animal Conflicts", Journal of Theoretical Biology, Vol. 47, pp. 209-221. 
Sutter, Matthias and Christina Strassmair, (2009), "Communication, Cooperation and Collusion in Team Tournaments-An Experimental Study", Games and Economic Behavior, Vol. 66, No. 1, pp. 506-525.

Vickrey, W. (1961), "Counterspeculation, Auctions, and Competitive Sealed Tenders", Journal of Finance, Vol. 16, No. 1, pp. 8-37.

Wawro, Gregory J. and Eric Schickler, (2006), Filibuster: Obstruction and Lawmaking in the U. S. Senate. Princeton University Press.

\section{A Appendix: uniform distribution (robustness test)}

In order to check whether some results of our analysis hold for another configuration of the distribution of values, we run an extra set of experiments. The only change relative to the previous sections is that we use a uniform distribution of values over all integers 1 through 60, instead of the skewed distribution depicted in Figure 1. In order to see if we obtain similar results, we run only two treatments - No Feedback and Simple Feedback-in a smaller sample. Table 9 provides the summary of the treatments.

Table 9: Summary of treatments; uniform distribution

\begin{tabular}{cccccc}
\hline Treatment & Sessions & Periods/session & $\sharp$ Players & $\sharp$ Votes & $\sharp$ Committees \\
\hline NF & 2 & $20 \& 30$ & 30 & 750 & 250 \\
SF & 2 & 30 & 30 & 900 & 300 \\
\hline Total & 4 & & 60 & 1650 & 550 \\
\hline
\end{tabular}

There is also a substantive lesson here. The theoretical prediction is that a less heterogeneous distribution of values makes it more difficult for supermajority to beat simple majority in terms of welfare. To be more precise, since the expected intensity of preferences is 30.5, the expected allocative welfare of simple majority is twice as large, 61. As it happens, it can be calculated that the theoretical expected allocative welfare achieved in the three-player waiting game with supermajority $m=1$ is also 61 . This 
prediction contrasts with our result for the skewed distribution, where supermajority was predicted to have a higher allocative welfare than simple majority.

The first row of Table 10 shows these values as well as theoretical net welfare and other benchmark values. The main message of this table is contained in its second and third rows, which show experimental results in No Feedback and Simple Feedback, respectively.

Table 10: Welfare; uniform distribution

\begin{tabular}{ccccccc}
\hline Treatment & $\begin{array}{c}\text { Allocative } \\
\text { Welfare }\end{array}$ & $\begin{array}{c}\text { Net } \\
\text { Welfare }\end{array}$ & $\begin{array}{c}\text { Waiting cost } \\
\text { per committee }\end{array}$ & $\begin{array}{c}\text { Simple } \\
\text { Majority }\end{array}$ & $\begin{array}{c}\text { First } \\
\text { Best }\end{array}$ & $\begin{array}{c}\text { Sum of } \\
\text { Values }\end{array}$ \\
\hline $\mathrm{NF}(\mathrm{th})$ & 61.0 & 39.5 & 21.5 & 61.0 & 63.4 & 91.5 \\
$\mathrm{NF}$ & 56.7 & 31.6 & 25.0 & 61.8 & 64.3 & 92.7 \\
$\mathrm{SF}$ & 55.5 & 25.1 & 30.4 & 62.7 & 65.3 & 95.3 \\
\hline
\end{tabular}

These data are summarized in Figure 5, which is equivalent to Figure 3. We see a very similar pattern: No Feedback allocative welfare is lower than its theoretical prediction, essentially due to noise that blunts sorting present in the theoretical equilibrium. The second similarity is that Simple Feedback generates lower allocative welfare than No Feedback. Thirdly, our previous results that waiting cost in Simple Feedback is greater than in No Feedback is confirmed too.

The only divergence is this: in the set of experiments with the skewed distribution, the No Feedback waiting time was similar to its theoretical prediction. With the uniform distribution, the No Feedback waiting time appears to be somewhat greater than its theoretical value. The known tendency to cluster exit times at zero appears to play a role here: this effect is greater when the distribution of values is concentrated around zero in our original set of experiments. Comparing the fraction of committee decisions made at zero we see that the uniform distribution has fewer of them, confirming that agents engage in a war of attrition more when the distribution is uniform. ${ }^{30}$

\footnotetext{
${ }^{30}$ Stoppage at zero occurs in $52.7 \%$ of committees in $\mathrm{NF}$ and $44.3 \%$ in $\mathrm{SF}$ when the distribution is skewed, while it drops to $26 \%$ in NF and $38 \%$ in SF when the distribution is uniform. At the same time, the effect of feedback appears inconsistent: feedback lowers the fraction of committees deciding at zero in the skewed distribution, but increases in the uniform distribution.
} 


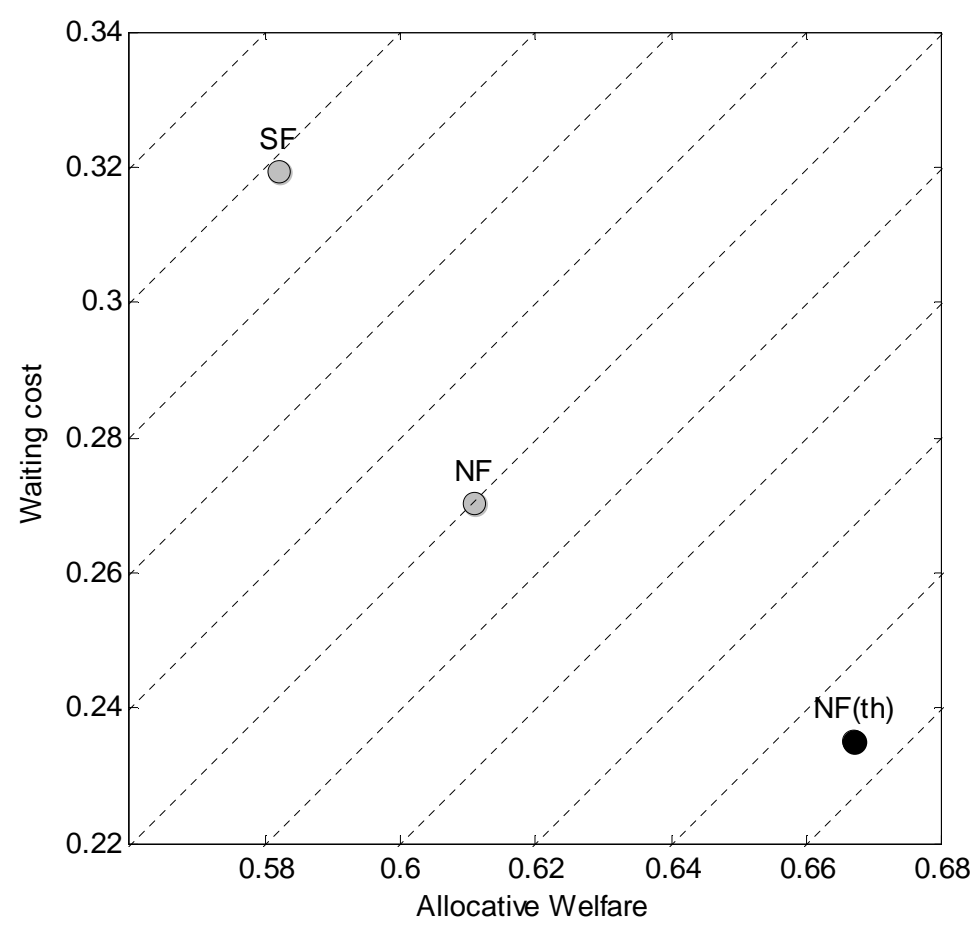

Figure 5: Allocative welfare vs waiting cost (by treatment, \% of Sum of Values).

Moving on to the issue of asymmetric collapse, we consider Table 11. As in our previous set of experiments summarized in Table 4, we see that feedback empowers minority - the frequency of minority winning goes up from approximately one third to $46.7 \%$, thus again confirming Conjecture 3(2).

Table 11: Incidence of winning by group; uniform distribution.

\begin{tabular}{cccc}
\hline Treatment & $\begin{array}{c}\text { Majority } \\
\text { (minority exit first) }\end{array}$ & $\begin{array}{c}\text { Majority } \\
\text { (majority exit first) }\end{array}$ & Minority \\
\hline $\mathrm{NF}$ & 31.6 & 35.2 & 33.2 \\
$\mathrm{SF}$ & 23.0 & 30.3 & 46.7 \\
\hline
\end{tabular}

All entries are in \%.

Next, we consider the instant exit hypothesis. Table 12 represents the same measures as Table 5. We see that with No Feedback, the percentage of committees in which the first leaver is a majority player is about two thirds - this increases to $77 \%$ when feedback is allowed. However, in contrast to the skewed distribution, the difference in exit times between two majority voters does not increase. 
Table 12: Instant exit hypothesis.

\begin{tabular}{ccc}
\hline Treatment & $\begin{array}{c}\text { \% of committees in } \\
\text { which 1st player to exit is } \\
\text { a member of the majority }\end{array}$ & $\begin{array}{c}\text { Absolute difference } \\
\text { in exit time between } \\
\text { two majority voters }\end{array}$ \\
\hline NF & 68.4 & 9.0 \\
SF & 77.0 & 7.9 \\
\hline
\end{tabular}

Finally, we observe a similar pattern of shifting misallocation as before. Since introducing feedback leads to minority winning more often, misallocation in minority win committees is lower, as depicted in Table 13; at the same time, misallocation in majority win committees is greater.

Table 13: Misallocation. Uniform distribution.

\begin{tabular}{cccc}
\hline Treatment & $\begin{array}{c}\text { Misallocation } \\
\text { minority win }\end{array}$ & $\begin{array}{c}\text { Misallocation } \\
\text { majority win }\end{array}$ & $\begin{array}{c}\text { Misallocation } \\
\text { overall }\end{array}$ \\
\hline $\mathrm{NF}$ & 36.4 & 26.5 & 28.2 \\
$\mathrm{SF}$ & 18.6 & 39.7 & 36.6 \\
\hline
\end{tabular}

All entries are in $\%$.

All in all, the additional experiments with uniform distribution reported in this section reveal similar patterns as identified in the previous section and they do confirm the theoretical prediction that high heterogeneity of preference intensity (skewed distribution) is a necessary condition for supermajority to be better in allocative terms than simple majority.

\section{B Appendix}

This Appendix gives an example of instructions, examples, and quizzes for the Simple Feedback treatment. 


\section{INSTRUCTIONS}

\section{Introduction}

Thank you for participating in this experiment on decision-making. During this experiment you will earn money. How much you earn depends on your decisions, the decisions of other participants, and an element of chance. This money will be paid to you, in cash, at the end of the experiment.

During the experiment we will speak in terms of Experimental Monetary Units (EMU), instead of Pounds. Your payoff will be calculated in terms of EMU and then converted to Pounds at the end of the experiment, at a rate of $1 \mathrm{EMU}=8$ pence. You will start the experiment with an initial endowment of $120 \mathrm{EMU}(£ 9.60)$.

After the instructions are read aloud and all the participants have understood them, the experiment will start. You will see the first screen, where you will have to type the number you received at the entrance. This will be your ID number. The experiment is divided into 40 periods. In each period, you will face the same situation described in the next section. After this, we will ask you to complete a short survey.

At the end of the experiment, the computer will randomly select three periods. The payoff that you obtained in these periods will be added to the initial endowment, and will make up the total amount of EMU earned in the experiment.

Please do not talk to anyone. Your participation in the experiment and any information about your earnings will be kept strictly confidential. Everyone will be paid in private and you are under no obligation to tell others how much you earned. Your receipt of payment and consent form are the only places on which your name will appear. This information will be kept confidential in the manner described in the consent form. 


\section{The group decision problem in each period.}

At the beginning of each period you will be randomly assigned to a three-member committee. The composition of your committee may vary from period to period.

The committee will select one of two alternatives through a procedure to be explained below.

You, and the other members of the committee, will receive a number that represents each member's respective valuation of their preferred alternative. Committee members do not know the valuations of other committee members, they only know their own.

This valuation can be any integer number between 1 and 60, but these numbers do not have the same chance of occurring. In particular, you are more likely to receive a small valuation than a large one. The Figure below shows the likelihood of receiving various valuations.

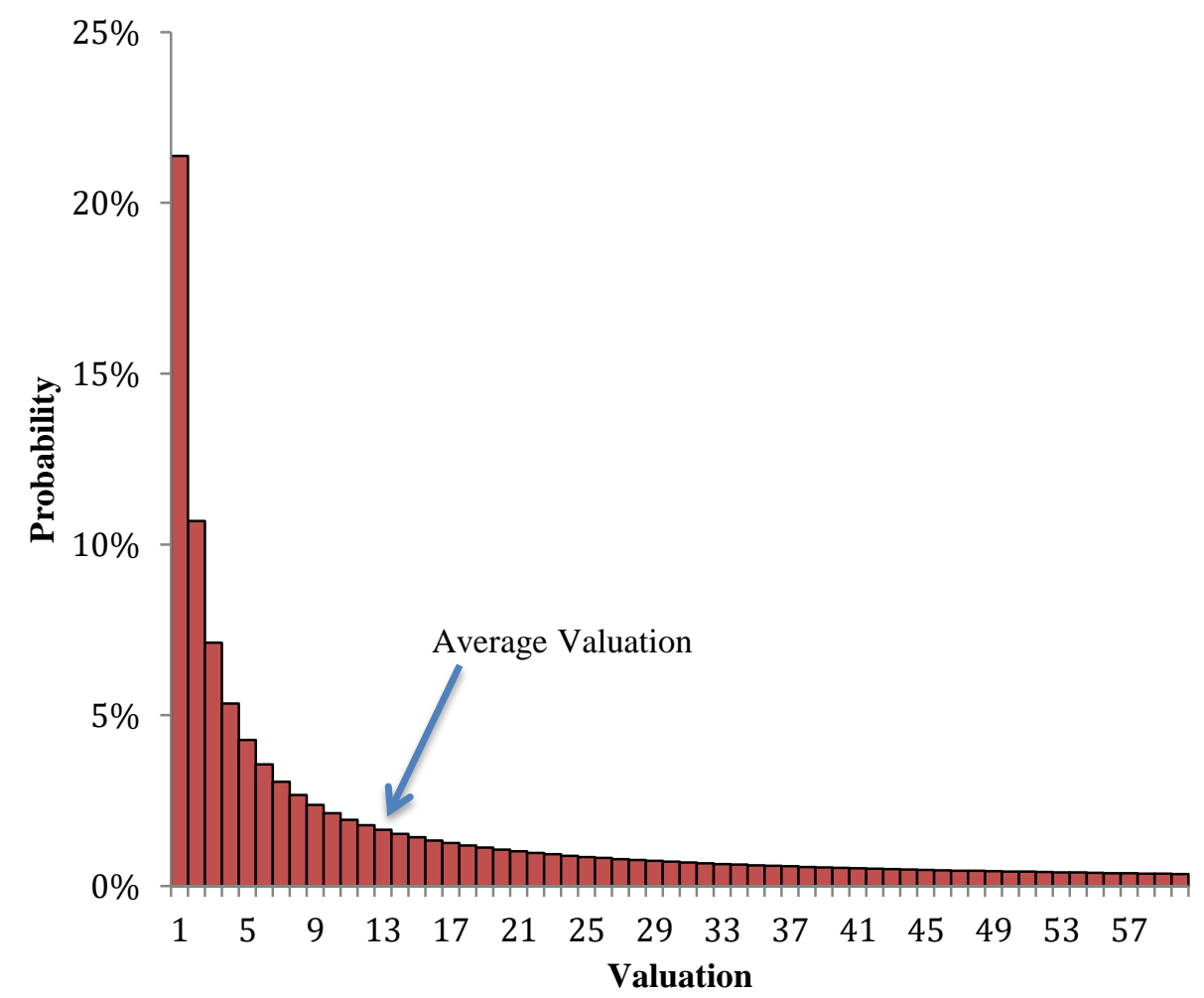

For example, the probability of receiving valuation 1 is just over $21 \%$. The probability of receiving valuation 2 is almost $11 \%$. The probability of receiving valuation 21 is $1 \%$. The probability of receiving valuation 60 is $0.36 \%$.

Notice also that the probability of receiving a valuation between 1 and 5, inclusive, is almost $50 \%$. The probability of receiving a valuation between 6 and 60 , inclusive, is just over $50 \%$. 
In every period and in every committee, there will be 1 member supporting one of the alternatives (group of 1), and 2 members supporting the other alternative (group of 2).

The committee decision in each period is made according to the following waiting game, which lasts at most 60 seconds. After each member receives a valuation, and learns whether they are in a group of 1 or 2 , the computer starts the clock.

- Initially, you are presumed to support your preferred alternative. To indicate that you want to cease supporting your alternative, you have to press the "EXIT" button. You may exit at any time. You may exit even before the clock starts, to indicate that you cease supporting your alternative immediately.

- The waiting game stops as soon as the last supporter of one of the alternatives exits. The alternative that still has supporters is selected by the committee.

- Waiting is costly. It costs 1 EMU per second to keep supporting your alternative. Your actual waiting cost is determined by your exit time, or the time when the waiting game stops.

The computer displays the clock showing how many seconds have elapsed since the beginning of the period. This is also your accumulated waiting cost in EMUs. Also, the computer will display a message as soon as any member exits the waiting game.

If an alternative is not selected after 60 seconds, the computer will stop the clock and select an alternative randomly, in proportion to the number of supporters at this time.

\section{Payoff calculation in each period.}

If your preferred alternative is selected, your payoff in EMUs will be equal to your valuation, minus the waiting cost. If your preferred alternative is not selected, then you do not get the valuation, but you still pay the waiting cost.

\section{Information at the end of each period.}

At the end of each period you will receive the following pieces of information.

1. Exit times of other members of the committee.

2. Whether you were in a group of 1 or 2 .

3. The alternative that was selected.

4. Your payoff in EMU. 


\section{Examples of how your payoff in a period is determined.}

Example 1.

Suppose that your valuation is 24 and you intend to exit 38 seconds into the waiting game. Suppose that it turns out that you were in a group of 2 and the other member of your group exits 8 seconds into the game, whereas the member of the group of 1 exits 19 seconds into the game. The waiting game stops 19 seconds into the game, when the last supporter of the other alternative exits. Your alternative is selected. Your period payoff will be: 24 minus your waiting cost 19, which equals 5 EMU.

Example 2.

Suppose that your valuation is 15 and you intend to exit 18 seconds into the game. Suppose that it turns out that you were in a group of 2 and the other member of your group exits 8 seconds into the game, whereas the member of the group of 1 intends to exit 19 seconds into the game. The waiting game stops 18 seconds into the game, when the last supporter of your alternative exits. Your alternative is not selected. Your period payoff will be: 0 minus your waiting cost 18 EMU.

\section{Example 3.}

Suppose that your valuation is 2 and you intend to exit 21 seconds into the game. Suppose that it turns out that you were in a group of 1 , and the two members of the group of 2 intend to exit 24 seconds, and 16 seconds into the game, respectively. The waiting game stops 21 seconds into the game, when the last supporter of your alternative exits. Your alternative is not selected. Your period payoff will be: 0 minus your waiting cost $21 \mathrm{EMU}$. 


\section{Comprehension questionnaire}

Question 1.

Suppose that your valuation is 1 and you intend to exit 3 seconds into the game. Suppose that it turns out that you are in a group of 1 and the two members of the group of 2 intend to exit 2 seconds and 1 second into the game, respectively.

The waiting game stops seconds into the game.

Your alternative (is / is not) selected.

Your payoff will be: $=$ EMU.

\section{Question 2.}

Suppose that your valuation is 53 and you intend to exit 22 seconds into the game. Suppose that it turns out that you are in a group of 2 and the other member of your group intends to exit 29 seconds into the game, whereas the member of the group of 1 intends to exit 27 seconds into the game.

The waiting game stops seconds into the game.

Your alternative (is / is not) selected.

Your payoff will be: $=$ EMU.

\section{Question 3.}

Suppose that your valuation is 28 and you intend to exit 11 seconds into the game. Suppose that it turns out that you are in a group of 1 and the two members of the group of 2 intend to exit 29 and 3 seconds into the game, respectively. The waiting game stops seconds into the game.

Your alternative (is / is not) selected.

Your payoff will be: $=$ EMU.

\section{Question 4.}

Suppose that your valuation is 3 and you intend to exit 17 seconds into the game. Suppose that it turns out that you are in a group of 2 and the other member of your group intend to exit 4 seconds into the game, whereas the member of the group of 1 intend to exit 18 seconds into the game.

The waiting game stops seconds into the game.

Your alternative (is / is not) selected.

Your payoff will be: $=$ EMU. 